\title{
Recent Research Developments in the Direct Inhibition of Coagulation Proteinases - Inhibitors of the Initiation Phase
}

\author{
Brian L. Henry and Umesh R. Desai* \\ Department of Medicinal Chemistry and Institute for Structural Biology and Drug Discovery, Virginia Commonwealth University, \\ Richmond, VA 23298, USA
}

\begin{abstract}
Physiologic clotting is a defensive action. The new cell-based model of hemostasis proposes three steps - initiation, amplification and propagation - occurring on specific cell surfaces to generate a thrombus in a tightly regulated manner. The initiation phase relies on key players including tissue factor (TF), factor VIIa (fVIIa), platelets, $\mathrm{Ca}^{2+}$, phospholipids, and factor X/Xa (fX/fXa). Exposure of TF on sub-endothelial and other blood cells triggers a coagulation response, which may have to be inhibited to prevent a deleterious thrombotic effect. Inhibiting TF-initiated coagulation, akin to 'nipping coagulation in the bud', is predicted to have major advantages, including a more efficient separation of the antithrombotic and hemorrhagic responses. The availability of crystal structures of TF, fVIIa and TFfVIIa complex makes structure-based drug design feasible. Although no initiation phase small molecule inhibitor has reached the clinic as yet, several molecules have displayed promise. We discuss recent results on the discovery of inhibitors of the initiation phase with special emphasis on peptides, peptidomimetics and organic small molecules.
\end{abstract}

Key Words: Anticoagulants, coagulation, factor VIIa, tissue factor, thrombin, factor Xa, Enzyme Inhibition, small molecule inhibitors.

\section{CELL-BASED HEMOSTASIS}

Physiologic clotting is a defensive action preventing excessive loss of blood and infiltration of microbes. The physiologic mechanism that produces this defensive reaction is an enzymatic cascade (Fig. 1), proposed nearly 50 years ago $[1,2]$. In vivo, the enzymatic reactions occur on specific cell surfaces. The cell-dependent coagulation cascade is proposed to proceed sequentially in three steps initiation, amplification and propagation - on specific cell surfaces to generate a thrombus in a tightly regulated manner [3-5].

\section{Initiation}

Tissue factor (TF) is an integral membrane protein present on several extravascular cells [6] and is the most important initiator of coagulation. Under normal conditions, it is sequestered from circulating proteinases, especially factor VII (fVII), thus preventing inappropriate initiation of clotting. Vascular injury exposes TF to blood, resulting in rapid complex formation with free activated fVII (fVIIa) on TF-bearing cells (Fig. 1). It is believed that some fVIIa is always present in blood $(\sim 1-2 \%)$, which can rapidly interact with $\mathrm{TF}$ to initiate clotting. The formation of TF/fVIIa complex activates the circulating factor $\mathrm{X}(\mathrm{fX})$ to $\mathrm{fXa}$, the formation of which can induce further production of fVIIa and fXa [7-9]. The TF/fVIIa complex can also activate factor IX (fIX) to fIXa [10-12], which in turn can result in more $\mathrm{fXa}$. The earliest $\mathrm{fXa}$ formed remains localized to the site of TF-bearing cells, yet is free enough to form the prothrombinase complex with factor $\mathrm{Va}(\mathrm{fVa})$. The small amount of the prothrombinase complex so formed is responsible for the initial production of thrombin from prothrombin [12]. The in vivo source of the initial fVa needed for the assembly of prothrombinase complex remains unclear, although several possibilities have been proposed [5].

\section{Amplification}

The small amount of thrombin formed on TF-bearing cells is sufficient to activate platelets that have adhered at the site of injury, thus initiating amplification of the coagulation signal. In addition, the formation of thrombin potentiates the proteolytic cleavage of $\mathrm{fV}$, fVIII and fXI [13-16], although a recent report throws some doubt on the role of fXI [17]. The initial levels of thrombin generated on or near the platelet surface also lead to cleavage of prote-

\footnotetext{
*Address correspondence to this author at the Department of Medicinal Chemistry, Virginia Commonwealth University, $410 \mathrm{~N} .12^{\text {th }}$ Street, PO Box 980540, Richmond, VA 23298-0540, USA; Tel: 804-828-7328; Fax: 804827-3664; E-mail: urdesai@vcu.edu
}

ase-activated receptors (PARs), which in turn induce further activation of platelets as well as the release of $\mathrm{fV}$.

\section{Propagation}

It is suspected that fVa, fVIIIa, fIXa, and fXa formed near activated platelets can bind certain cellular receptors, although the receptors have not been unambiguously identified. This helps to localize the amplified procoagulant signal. Additionally, the close proximity of the coagulation enzymes induces the formation of the intrinsic tenase (fVIIIa + fIXa) and prothrombinase (fXa $+\mathrm{fVa})$ complexes, which possess robust catalytic activity for the production of fXa and thrombin, respectively, thus assembling a 'pipeline' for rapid thrombin synthesis. The 'pipeline' is fed the necessary catalytic factors (fIXa and fXa) through the actions of activated platelets. Platelets also bind fibrinogen, which is cleaved into fibrin monomers by thrombin. Non-covalent, self-association of fibrin monomers produces a loose clot. This is subsequently covalently cross-linked by factor XIIIa, which enhances the structural integrity of the growing thrombus [18]. In essence, activated platelets are the 'platform of all action' (Fig. 1) [3-5, 19].

While chemical processes are rapidly generating polymeric fibrin, physical association of activated platelets continues in a coordinated manner to produce an adequate thrombus. During thrombogenesis, clotting factors including thrombin, $\mathrm{fXa}$, prothrombinase complex, and others, become ensnared in the growing threedimensional network. Of these, thrombin is known to bind to fibrin. The clot-bound factors do not loose their proteolytic activity and clot dissolution may reactivate thrombogenesis. The presence of activated platelets and active clotting factors implies that a clot is a dynamic system, which evolves as it matures [20,21].

The goal of the enzymatic cascade is to form a stable clot and seal off the area of hemorrhage. However, this defensive reaction requires a regulator to control the process as well as prevent unnecessary or excessive activation. Several proteins in our body regulate the procoagulant response including antithrombin (AT) [22], activated protein C (APC) [23] and tissue factor pathway inhibitor (TFPI) [24]. These endogenous inhibitors prevent hyper-coagulation by inhibiting the cascade at multiple points (Fig. 2). Antithrombin is a major regulator of thrombin, fXa, and fIXa [22, 25] under physiological conditions and probably also inhibits fVIIa [26] and fXIa $[25,27]$ to some extent. A major player in the antithrombin regulation of coagulation enzymes is heparin/heparan sulfate, which induce a massive $300-4,000$-fold increase in the rate of inhibition [28]. In contrast to antithrombin, TFPI inhibits fXa and the TF/fVIIa/fXa complex exclusively [24]. Paradoxically, the 

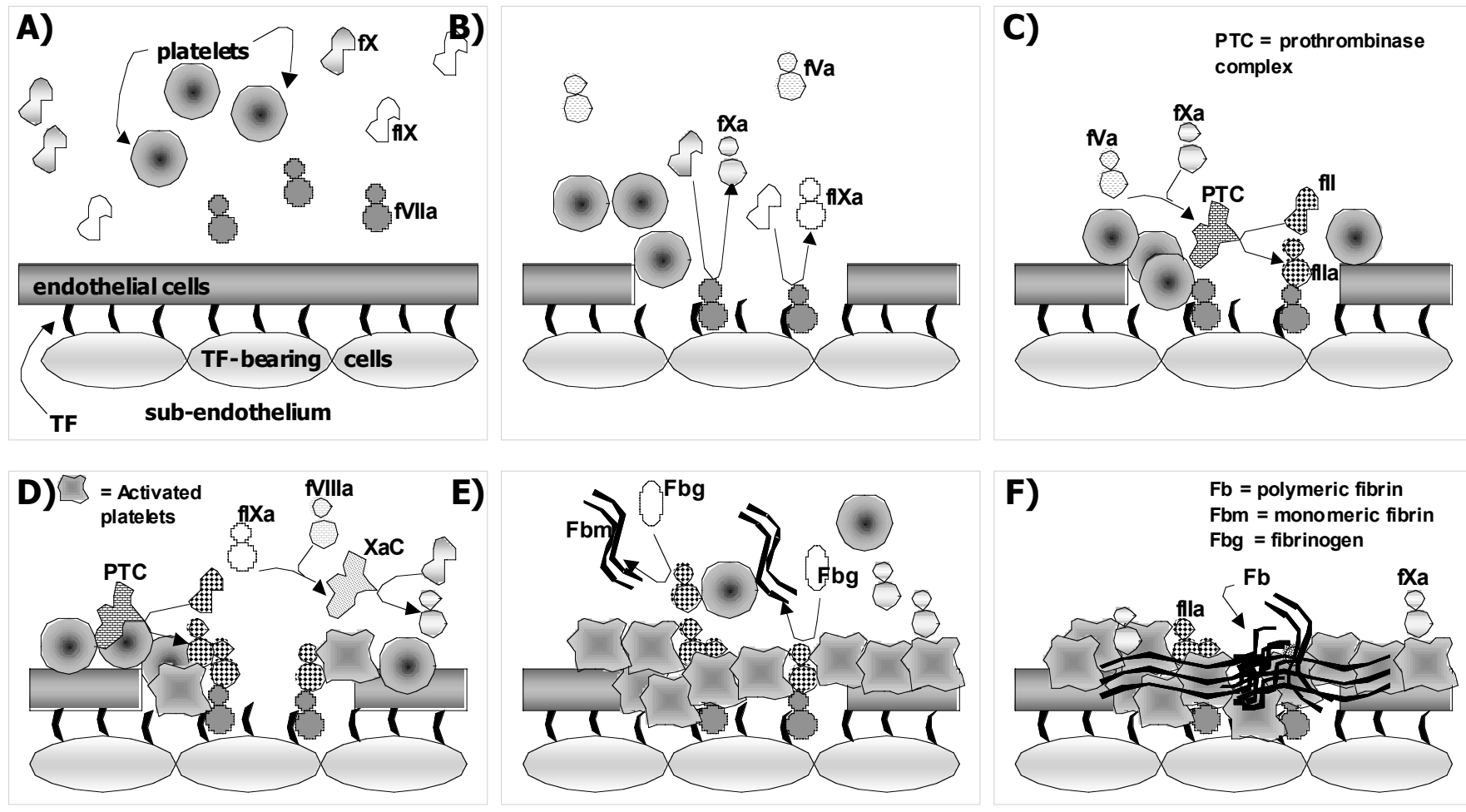

Fig. (1). Cell-based model of hemostasis. A) Tissue factor (TF) is the most important initiator of coagulation. Normally TF is protected from the vasculature, which contains free activated fVII (fVIIa) ready for initiation of coagulation. B) Vascular injury exposes TF to the vasculature for rapid complex formation with fVIIa, which in turn activates blood-borne factor X (fX) to fXa. The TF/fVIIa complex also activates factor IX (fIX) to fIXa. C) The earliest fXa formed remains localized to site of TF-bearing cells, yet is free enough to form prothrombinase complex (PTC) with factor Va (fVa) for the initial production of thrombin (fIIa) from prothrombin (fII). D) The small amount of thrombin so formed is sufficient to activate platelets that have adhered at the site of injury and induce cleavage of proteinases fV, fVIII and fXI (not shown). The formation of activated forms of $\mathrm{fV}$ and fVIII as well as activation of platelets sets the stage for rapid generation of thrombin. Intrinsic tenase (fVIIIa + fIXa) and prothrombinase (fXa $+\mathrm{fVa}$ ) complexes are assembled on the platelet surface. E) The final step is cleavage by fIIa of fibrinogen (Fbg) to fibrin monomers (Fbm). F) Non-covalent self-association of these monomers produces a 'loose' clot, which is covalently cross-linked by factor XIIIa (fXIIIa) to form rigid, insoluble fibrin mesh (Fb).

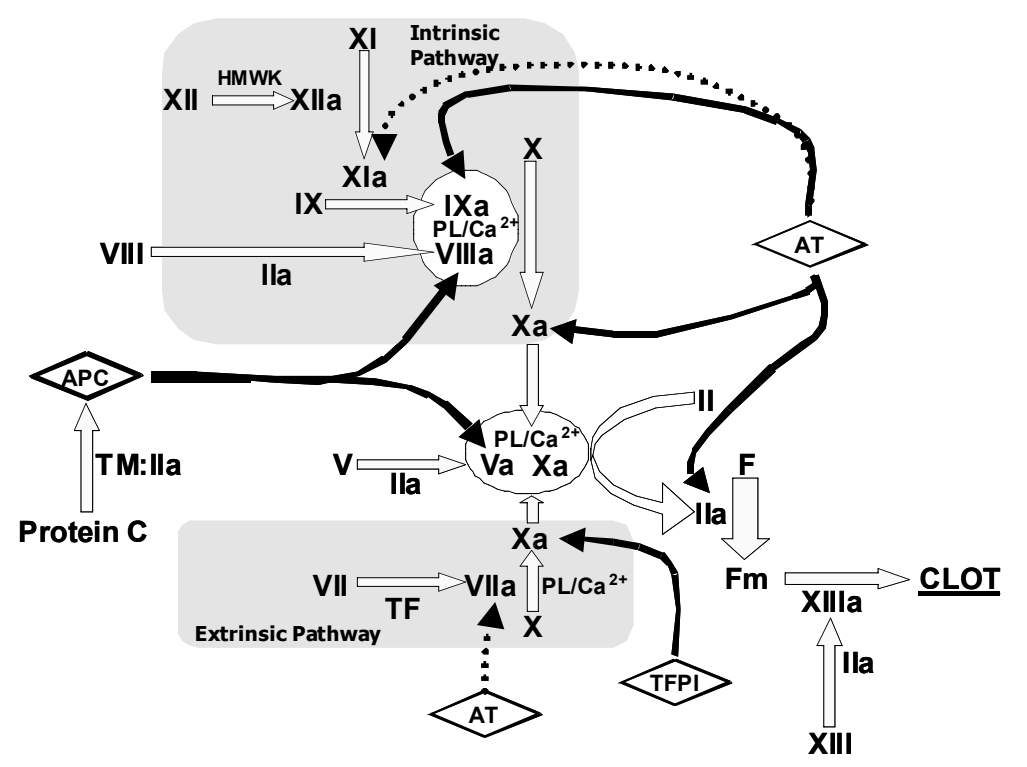

Fig. (2). Endogenous regulators of the coagulation cascade include antithrombin (AT), tissue factor pathway inhibitor (TFPI) and activated protein C (APC). These inhibitors target several proteinases of the cascade. For example, AT primarily targets fXa, fIXa and thrombin (bold red colored arrows) and secondarily may target fVIIa and fXIa (dotted red colored arrows), TFPI targets Xa, while APC targets fVIIIa and fVa. Collectively these inhibitors prevent a hypercoagulated state. See text for details. HMWK = high molecular weight kininogen; PL = phospholipid; TM = thrombomodulin; TM:IIa = thrombomodulin - thrombin complex; $\mathrm{TF}=$ tissue factor; $\mathrm{F}=$ fibrinogen; Fm = fibrin monomers. 
normally pro-coagulant proteinase thrombin behaves as an anticoagulant when its concentrations reach a level sufficient to bind to thrombomodulin (TM) and activate protein $\mathrm{C}$, which in turn inhibits fVa and fVIIIa (Fig. 2) [23]. Overall, TFPI inhibits the earliest steps of coagulation, while AT and APC target the process of amplification and propagation.

\section{CURRENT STATUS OF ANTICOAGULATION THERAPY}

Nearly 576,000 new cases of deep vein thrombosis (DVT) and pulmonary embolism (PE), two of the most common thrombotic complications, are diagnosed every year in the US alone [29]. Thrombotic disorders are also 3 -fold more likely in people with cancer $[30,31]$ and are the underlying cause of $38 \%$ of all noncommunicable disease-related deaths worldwide [32]. These disorders are currently treated with heparins, coumarins, hirudins, and peptidomimetic small molecules. Unfractionated heparin (UFH) and warfarin (Fig. 3), discovered in 1916 [33] and 1941 [34], respectively, are still used in much the same form today, while newer derivatives include low-molecular-weight heparins (LMWHs, Fig. 3) and a synthetic pentasaccharide, fondaparinux (Fig. 3).

The heparins (UFH, LMWH and fondaparinux) and the coumarins (warfarin, dicoumarol, etc.) are indirect inhibitors that require intermediary co-factors to mediate their anticoagulant effects. Whereas the heparins require antithrombin, the coumarins require vitamin $\mathrm{K}$ epoxide reductase. Although these drugs have been the mainstay of anticoagulant therapy for the past several decades, use of both these agents is problematic. The coumarins suffer from narrow therapeutic index window and drug - drug or drug - food adverse reactions, while UFH suffers from enhanced bleeding complications, patient-to-patient response variability, platelet function inhibition, heparin-induced thrombocytopenia (HIT), and osteoporosis [35]. Importantly, heparins do not neutralize clot-bound thrombin [36-38], which implies that re-activation of clotting may occur at a later time [39]. LMWHs also suffer from similar problems, although the number of bleeding episodes is lower and response variability is reduced [40-44]. Fondaparinux is perhaps the best anticoagulant in this series with no HIT and predictable patient response. Yet, it too does not completely eliminate the risk of bleeding and lacks an effective antidote to reverse excessive iatrogenic bleeding [45-49]. Additionally, all heparins suffer from poor oral bioavailability. Interest in developing new heparins continues unabated $[28,50]$. A new pentasaccharide called idraparinux is being developed as once-a-week injection, but because of its structural similarity to fondaparinux it is likely to carry a similar bleeding risk and antidote problem [51-54].

In contrast to indirect inhibition, direct inhibition has been suggested to be a better strategy. Direct inhibition does not require an intermediary protein to mediate the anticoagulant effect. Rather it involves the direct binding of an inhibitor to a procoagulant proteinase, e.g., thrombin or factor $\mathrm{Xa}$, to generate the anticoagulation effect [55-57]. Hirudin, bivalirudin and argatroban (Fig. 4) are three parenteral direct thrombin inhibitors (DTIs) approved for clinical use [58, 59], while ximelagatran and dabigatran etexilate (Fig. 4) have been extensively investigated as oral DTIs. Likewise, the small molecule pro-drugs, DX9065a and razaxaban, are being pursued as direct factor Xa inhibitors [60-62].

Direct inhibition promises to offer the important advantage of inhibiting both free and clot-bound thrombin as well as factor Xa present in the prothrombinase complex [63-66]. Direct inhibitors are also less likely to bind plasma proteins non-specifically, thus offering a more predictable patient response. However, significant challenges remain. The hirudins have been associated with major bleeding episodes limiting their use in patients refractory to UFH. Bivalirudin (Fig. 4) has a much shorter half-life $(25 \mathrm{~min})$ because thrombin cleaves its $\mathrm{Arg}^{3}-\mathrm{Pro}^{4}$ bond. Argatroban appears to have no major adverse effects, but it too has short half-life and is associated with bleeding risk. An additional deficiency remains with most direct peptidomimetic inhibitors, most of which are not orally bioavailable. To address this, ximelagatran was developed as a prodrug of melagatran (Fig. 4). Although ximelagatran was approved for clinical use in Europe, the US FDA rejected its application in 2004 due to concerns of hepatotoxicity [67]. Recent studies suggest that direct inhibitors that use a basic group as a P1-arginine mimic

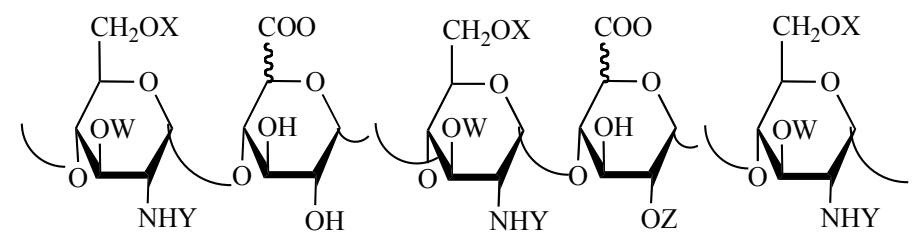

$\mathrm{X}=-\mathrm{SO}_{3}$ or $-\mathrm{H} ; \quad \mathrm{Y}=-\mathrm{SO}_{3}$ or $-\mathrm{COCH}_{3}$

$\mathrm{Z}=-\mathrm{SO}_{3}$ or $-\mathrm{H} ; \quad \mathrm{W}=-\mathrm{SO}_{3}$ or $-\mathrm{H}$

$\mathrm{UFH}::$ MR $=\sim 15,000 ; \quad$ LMWH:: $\mathrm{MR}=\sim 5,000$<smiles>CC(=O)CC(c1ccccc1)c1c(O)c2ccccc2oc1=O</smiles>

Warfarin<smiles>O=c1oc2ccccc2c(O)c1Cc1c(O)c2ccccc2oc1=O</smiles>

Dicoumarol

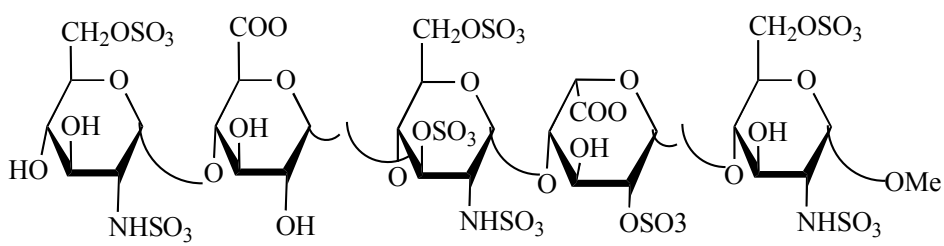

Fondaparinux

Fig. (3). Structures of current clinically available indirect oral anticoagulants. Most commonly used agents include heparins (UFH and LMWH) (A), coumarins (warfarin and dicoumarol) (B) and the synthetic pentasaccharide, fondaparinux (C). W, X, Y, and Z in (A) refer to possible $-\mathrm{H},-\mathrm{SO}_{3}{ }^{-}$or $-\mathrm{COCH}_{3}$ substituents, while numbers 1 and 4 refer to the position of inter-glycosidic linkages. 


$$
\begin{gathered}
\mathrm{H}_{2} \mathrm{~N}-\mathrm{D}-\mathrm{Phe}-\mathrm{Pro}-\mathrm{Arg} \text {-Pro-Gly-Gly-Gly-Gly-Asn-Gly} \\
\text { HOOC-Leu-Tyr-Glu-Glu-Pro-Ile-Glu-Glu-Phe-Asp } \\
\text { Bivalirudin }
\end{gathered}
$$

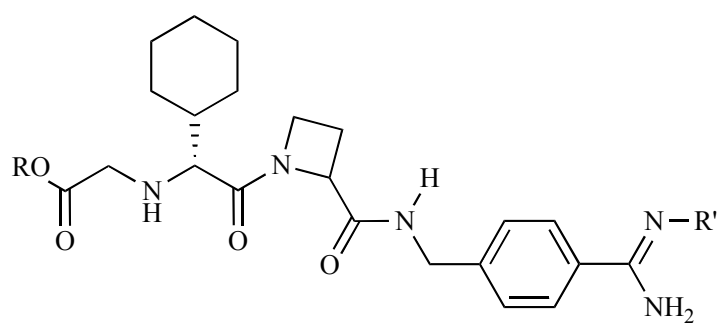

Ximelagatran $\mathrm{R}=-\mathrm{CH}_{2} \mathrm{CH}_{3} \mathrm{R}^{\prime}=-\mathrm{OH}$

Melagatran $\quad \mathrm{R}=-\mathrm{H} ; \quad \mathrm{R}^{\prime}=-\mathrm{H}$<smiles>CC(=N)N1CC[C@H](Oc2ccc([C@@H](Cc3ccc4ccc(C(=N)N)cc4c3)C(=O)O)cc2)C1</smiles>

DX-9065a<smiles>C[C@H]1CCC(C(=O)[C@H](CCCNC(=N)N)NS(=O)(=O)c2cccc3c2NC[C@H](C)C3)[C@@H](C(=O)O)C1</smiles>

Argatroban<smiles>[R]N=C(N)c1ccc(NCc2nc3cc(C(=O)N(CCC([R20])=O)c4ccccn4)ccc3n2C)cc1</smiles>

Dabigatran etexilate $\mathrm{R}=-\mathrm{CH}_{2} \mathrm{CH}_{3} \quad \mathrm{R}^{\prime}=-\mathrm{COO}-\mathrm{nC}_{6} \mathrm{H}_{13}$ Dabigatran<smiles>CNCc1nccn1-c1ccc(NC(=O)c2cc(C(F)(F)F)nn2-c2ccc3onc(N)c3c2)c(F)c1</smiles>

Razaxaban

Fig. (4). Structures of direct thrombin and factor Xa inhibitors. Direct thrombin inhibitors include bivalirudin, argatroban, ximelagatran, melagatran, and dabigatran, while DX-9065a and razaxaban inhibit factor Xa directly. Shaded oval represents the guanidine or amidine group that mimics the arginine side chain of the P-1 residue recognized by thrombin and factor Xa.

for recognizing the enzyme appear to have another side effect - the degranulation of mast cells leading to histamine release [68, 69]. Finally, trials with ximelagatran, and other direct inhibitors, e.g., dabigatran, DX9065a and razaxaban, show the persistence of bleeding risk [56, 57, 60-64]. Thus, major challenges with direct inhibitors include establishing an enzyme affinity that is not associated with excessive bleeding, avoiding liver toxicity, eliminating histamine release, achieving oral bioavailability and maintaining sufficient duration of action.

\section{INHIBITING THE INITIATION PHASE}

The initiation of coagulation is occurs exclusively through tissue factor (TF), which becomes exposed to blood following vascular injury. TF binds to fVIIa and initiates the coagulation cascade. Alternatively in a diseased state, blood-borne TF, which is constitutively expressed in many cell types and is normally shielded from interacting with blood components, becomes exposed on ruptured cells, thereby triggering an internal clotting signal [70, 71]. Also, atheromatous plaques have increased levels of $\mathrm{TF}$, which upon destabilization is capable of initiating an acute thrombotic event $[70,71]$. Thus, no matter whether TF is derived from the subendothelium, blood-borne or atheromatous plaques, inhibiting TFinitiated coagulation - 'nipping the bud' - is expected to have major advantages. Inhibiting initiation is expected to prevent the subsequent downstream events, especially the generation of thrombin, excessive inhibition of which is thought to result in enhanced bleed- ing. This gives rise to a concept that a more efficient separation of antithrombotic and hemorrhagic responses may be possible through inhibition of TF-initiated coagulation [72]. In fact, active site inhibited fVIIa (fVIIai) was noted to induce no hemorrhagic complication when administered prior to angioplasty in baboons, while hirudin prolonged bleeding times [73]. One can also conjecture that modulators of TF, fVIIa or TF/fVIIa complex function would possess other advantages. For example, TF is a membrane protein that specifically recognizes fVIIa. Given the reasonable structural similarity of coagulation proteinases (fXa, thrombin, fIXa, etc.), it may be easier to design specific inhibitors of $\mathrm{TF}-\mathrm{fVII}$ interaction rather than specific inhibitors of other coagulation enzymes. Finally, other advantages of TF/fVIIa inhibition include a possible decrease in restenosis as well as a decrease in lesion formation [72].

\section{INTERACTION OF TF WITH COAGULATION FACTORS}

Tissue factor interacts with several coagulation proteins during the process of initiating a coagulation signal. Kinetic studies show that free fVIIa is not a potent enzyme and its activity greatly increases upon binding to TF [74-77]. This indicates that TF induces a change in the conformation of fVIIa, especially its active site, which is important for better recognition of substrates for proteolysis. Comparison of the crystal structures of fVIIa in complex with TF and zymogen fVII show that the enzyme's $N$-terminal residue, $\mathrm{Ile}^{16}$, is inserted into a pocket such that its hydrophobic side chain is shielded from solvent, while its cationic amino group forms a salt 
bridge with the acidic side chain of $\mathrm{Asp}^{194}$, which probably restrains active site $\operatorname{Ser}^{195}$, thus allowing catalysis to proceed smoothly [7881].

In addition to this allosteric effect on the active site of fVIIa, TF also provides a surface for interaction with fVIIa substrates, i.e., zymogens fX and fIX. Site-directed mutagenesis studies indicate that the region encompassed by $\mathrm{Tyr}^{157}, \mathrm{Lys}^{159}, \mathrm{Ser}^{163}, \mathrm{Gly}^{164}$, Lys $^{165}$, Lys ${ }^{166}$, and Tyr ${ }^{185}$ of TF recognizes fIX and fX [82-84]. This region has considerable surface area $\left(\sim 1100 \AA^{2}\right)$ and a net positive charge, but also has several hydrophobic groups [84]. This implies that it should be possible to target this exosite on $\mathrm{TF}$ as an approach to design potent, specific antithrombotic agents, although this approach appears to have not been explored.

The fX or fIX interfaces that recognize TF have also been investigated extensively. Domain swap mutagenesis has implicated the involvement of $\mathrm{XX}$ 's Gla and EGF1 domains in recognition of TF-fVIIa complex $[81,85-88]$. Likewise, both these domains play a role in fIX-TF-fVIIa interaction, although their relative importance is perhaps lower than that for $\mathrm{fX}$ [87]. Additional mutagenesis studies reveal that $\mathrm{Gly}^{48}$ in the EGF1 domain of fIX plays a significant role in its activation by TF-fVIIa complex [89]. Extensive modeling studies by Chen et al. [90] support the conclusion that Gla and EGF1 domains of fIX are involved in binding TF - fVIIa complex, while Norledge et al. [91] suggest that $\mathrm{Glu}^{51}$ and $\mathrm{Asn}^{57}$ in EGF1 domain and Asp ${ }^{92}$ and Asp ${ }^{95}$ in EGF2 domain of $\mathrm{XX}$ are important in this recognition. The Gla and EGF1 domains of $\mathrm{fX}$ and fIX are extensive with large surface area, however it appears that no molecule has been designed that utilizes this interface to inhibit the initiation phase of coagulation.

\section{STRUCTURE OF FVIIA}

Factor VIIa is a serine proteinases belonging to the trypsin family, which recognize amino acid sequences of the Arg-X type. Several crystal structures have been reported in various form, e.g., free fVIIa [92-94], active-site inhibited fVIIa [95-97], and in complex with TF [79]. The structures show that fVIIa resembles other coagulation proteinases in overall fold and disposition of catalytic triad (His ${ }^{57}, \mathrm{Asp}^{102}$ and $\mathrm{Ser}^{195}$ ). Factor VIIa consists of negatively charged Asp ${ }^{189}$, which serves to recognize positively charged Arg present on the $N$-terminal side of the scissile bond. The fVIIa active site can be thought of as a funnel at the stem of which lies Asp ${ }^{189}$, while at the rim are arranged two loops - the 60s-loop and the $95 / 100-$ loop (Fig. 5). The catalytic triad is organized approximately at the mid portion of the funnel, and is flanked by the Cys ${ }^{58}-\mathrm{Cys}^{42}$ primary S1 substrate selectivity pocket is a relatively narrow channel for hosting the long Arg side chain. Besides the S1 pocket, fVIIa's active site contains a proximal and a distal recognition site, the so-called S2 and S3 pockets, respectively. These regions determine the secondary selectivity of substrate recognition. The S2 pocket is fairly well defined by the 60s- and 95/100-loops, while the $\mathrm{S} 3$ pocket is an area approximately flanked by the $95 / 100$ - and $214 / 216$ loops.

The overall organization of fVIIa active site in terms of the Asp $^{189}$ residue, the catalytic triad, and the flanking loops is similar to other coagulation enzymes, however significant differences exist. For example, thrombin has an extensive 60 s-loop consisting of nine residues which reduce the volume of the $\mathrm{S} 2$ pocket considerably. More specifically, the side chain of $\operatorname{Trp}^{60 \mathrm{D}}$ introduces considerable steric hindrance for binding in the S2 pocket. In contrast, fXa has no additional residues in the 60s-loop, while fVIIa has four (Lys ${ }^{60 \mathrm{~A}}$, $\mathrm{Ile}^{60 \mathrm{~B}}$, Lys ${ }^{60 \mathrm{C}}$, and $\mathrm{Asn}^{60 \mathrm{D}}$ ). An important difference in this region for fVIIa is the presence of $\mathrm{Asp}^{60}$, which is not present in other coagulation enzymes and can serve as a residue for selective recognition.

Major differences in coagulation enzymes also exist in the 95/100-loop. Whereas the sequence is $\mathrm{Val}^{95}-\mathrm{Pro}^{96}-\mathrm{Gly}^{97}-\mathrm{Thr}^{98}$ -

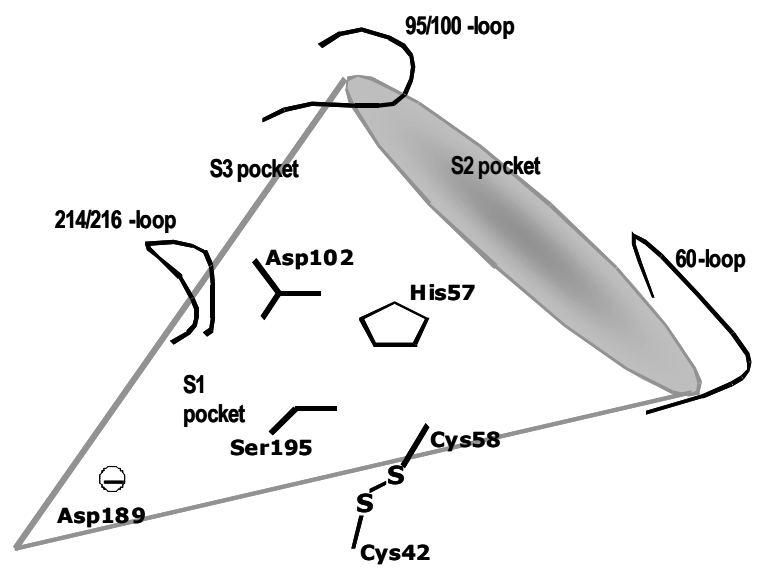

Fig. (5). A representation of the active site of fVIIa. The active site can be thought of as a funnel at the stem of which lies Asp ${ }^{189}$, while at the rim are arranged the $60 \mathrm{~s}-$ and the $95 / 100$ loops. The catalytic triad is organized approximately at the mid portion of the funnel, which is flanked by the $\mathrm{Cys}^{58}$ $\mathrm{Cys}^{42}$ disulfide bond on one side and the 214/126-loop on the other. The primary substrate selectivity S1 pocket is a relatively narrow channel for hosting Arg side chain, while S2 pocket is bordered by the 60s- and 95/100 loops. S3 pocket is approximately enclosed by the $94 / 100$ - and $214 / 216$ loops. See text for details.

$\mathrm{Thr}^{99}-\mathrm{Asn}^{100}$ in fVIIa, it is $\mathrm{Thr}^{95}-\mathrm{Lys}^{96}-\mathrm{Glu}^{97}-\mathrm{Thr}^{98}-\mathrm{Tyr}^{99}-\mathrm{Asp}^{100}$ in fXa and $\mathrm{Asn}^{95}-\mathrm{Trp}^{96}-\mathrm{Arg}^{97}-\mathrm{Asn}^{98}-\mathrm{Leu}^{99}-\mathrm{Asp}^{100}$ in thrombin. These completely different sequences implies that either this loop is not important at all in substrate recognition, or that it plays a selective role for only few enzymes $[98,99]$. For example, the presence of $\mathrm{Tyr}^{99}$ in the S2 pocket of fXa is likely to be an important filter, while $\operatorname{Trp}^{96}$ adds to the reduction in the size of the $\mathrm{S} 2$ pocket. The distal S3 pocket is diffuse and does not constrain substrate specificity, since it can host a large number of substrate structures. Several loop residues participate in defining this region including the $214 / 216$-loop consisting of $\operatorname{Trp}^{215}$, which is present in fVIIa, thrombin, $\mathrm{XXa}$, and fIXa in an identical orientation. The S3 pocket is primarily hydrophobic in these enzymes and allows for binding of a large number of different molecular scaffolds. Thus, despite the similarity of the overall fold, subtle differences exist in these coagulation enzymes, which are typically exploited in engineering specific inhibitors.

Other pathways for inhibition of fVIIa are theoretically possible. For example, the crystal structure of TF - fVIIa complex shows that the light chain of the proteinase wraps around TF to result in a massive $1340 \AA^{2}$ protein-protein contact area [79]. Mutagenesis studies indicate that most of the binding energy arises from the Gla and EGF1 domains, although EGF2 domain also contributes [100]. This presents a major opportunity of designing antagonists of TF fVIIa interaction, yet no such molecule has been reported.

\section{POTENTIAL PATHWAYS OF INHIBITING THE INITIA- TION PHASE}

The cascade of events that catalyze the initiation phase of coagulation include the exposure of $\mathrm{TF}$, the formation of $\mathrm{TF} / \mathrm{fVIIa}$ complex, and the binding of fX or fIX to the TF/fVIIa complex. Each of these processes could be targeted to inhibit the initiation phases. For example, molecules that engage the active site of fVIIa in complex with TF (path ' $a$ ', Fig. 6) or engage the active site in free enzyme (path ' $b$ ') are potent anticoagulants. An alternative to this competitive inhibition is non-competitive inhibition, or allosteric inhibition, in which molecules may bind an exosite on fVIIa (free or bound form), which alters the catalytic efficiency of the enzyme (path ' $c$ '). Likewise, agents that bind zymogens fX or fIX such that recognition of the active site in TF-fVIIa complex is im- 


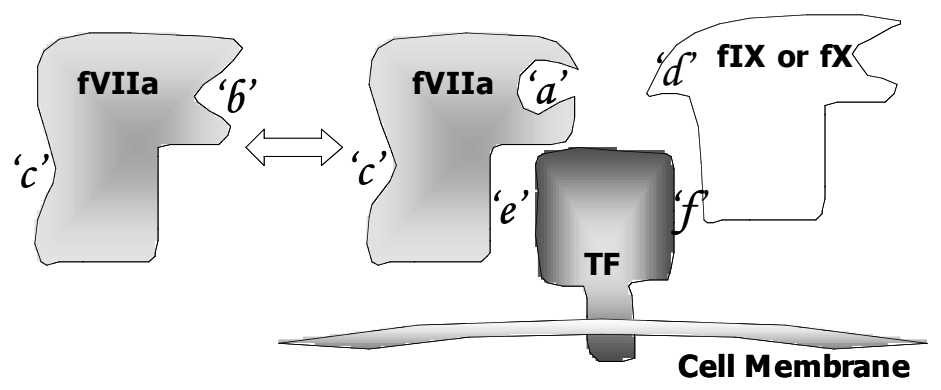

Fig. (6). Processes that could be targeted to inhibit the initiation phase include active site or allosteric modification of fVIIa proteolytic activity either in complex with TF or in free state (paths ' $a$ ' and ' $b$ '); allosteric modulation of fVIIa or fVIIa in complex with TF (path ' $c$ '); interaction with fIX or fX to antagonize binding in active site of fVIIa (path ' $d$ '); antagonism of TF recognition of fVIIa (path ' $e$ '); and antagonism fX or fIX recognition of TF in TF/fVIIa complex (path ' $f$ '). See text for details.

paired (path ' $d$ ') function as anticoagulants. Alternatively, the pathway of engaging an exosite on TF to antagonize binding to fVIIa, or vice versa, is also possible (path 'e', Fig. 6). Finally, another possibility is to design molecules that target fX or fIX such that their interaction with exosites on TF-fVIIa complex is impaired (path ' $f$ ', Fig. 6). The majority of inhibitors designed so far utilize pathways ' $a$ ' and ' $b$ ', while some exploit pathways ' $c$ ' and ' $d$ '. As our understanding of protein - protein recognition in the initiation phase of coagulation improves it is expected that molecules that utilize pathways ' $e$ ' and ' $f$ ' will emerge.

Although the concept of fVIIa inhibition has been around for some time, the past few years have seen a dramatic rise in number of molecules explored to inhibit the initiation phase. These molecules include protein/peptide-based inhibitors, small peptidomimetics, small organic molecules and natural products. A selection of these molecules is reviewed with special focus on recent reports. We have tried to pool a range of different structures, rather than being comprehensive, with the result that we may have not given due justice to the work of some authors.

\section{PROTEIN/PEPTIDE INHIBITORS OF INITIATION PHASE}

\section{Tissue Factor Pathway Inhibitor and its Derivatives}

Tifacogin is a recombinant form of TFPI [101]. TFPI is a 276 amino acid endogeneous inhibitor of fXa, which is released into circulation by exposure to heparin. TFPI consists of three structural domains, each of which performs an important function. The third domain binds heparin, while the second domain engages the active site of fXa and inactivates it. Following the formation of a binary fXa - TFPI complex, the first domain of TFPI binds in the active site of TF-fVIIa complex resulting in inhibition of the initiation signal.

Tifacogin is expressed in bacteria and has a single additional alanine at the $N$-terminus and is not glycosylated. The mechanism of tifacogin inhibition of TF-fVIIa is identical to TFPI, which is a Kunitz-type inhibitor of fXa. Although tifacogin was expected to have potential therapeutic effect in the treatment of sepsis, it has been shown not to be as effective [102]. Two patents describe the use of tifacogin in inhibiting microvasculature thrombosis [103].

\section{Active Site Inhibited fVIIa}

This is a recombinant form of human fVIIa in which the active site has been covalently inactivated by the inhibitor Phe-Phe-Arg chloromethyl ketone [72]. Factor VIIai competes with endogenous fVIIa for binding to TF, however because it is catalytically inactive, it serves as an antagonist of coagulation [72]. Although fVIIai is a promising antithrombotic in animal models, it was found that fVIIai therapy did not produce major reduction in death or myocardial infraction, while the rates of major bleeding were similar to therapy with heparin. These results led to the halt of development of fVIIai as a viable antithrombotic [104].

\section{E-76 and A-183}

In an excellent application of bacteriophage library - based inhibitor design, Lazarus and co-workers describe the identification of an 18-mer peptide E-76 (Ac-ALCDDPRVDRWYCQFVEG$\mathrm{NH}_{2}$ ) that inhibits fVIIa with $1 \mathrm{nM} \mathrm{IC}_{50}$ [105]. Binding studies showed that E-76 binds both fVIIa and TF-fVIIa complex with an identical affinity of $8.5 \mathrm{nM}$, while it does not interact with any other coagulation protein. Binding of E-76 to fVIIa was independent of the active site alkylation suggesting that E-76 engages an allosteric exosite on fVIIa. Kinetic studies revealed that E-76 disrupted the catalytic apparatus such that it reduced the $k_{\mathrm{CAT}}$ of $\mathrm{fX}$ activation. Thus, E-76 is the first initiation phase inhibitor that belongs to the path ' $d$ ' class (Fig. 6). The discovery of this inhibitor opens up a new avenue for structure-based rational design of peptido-mimetics or small molecule inhibitors that target this pathway.

The investigators have identified the most important residues in E-76 and have solved the structure of E-76 in complex with Gladomainless fVIIa [105]. Several hydrophobic residues of E-76 have major impact on $\mathrm{fX}$ activation including $\mathrm{Phe}^{15}, \mathrm{Tyr}^{12}, \operatorname{Trp}^{11}$, and $\mathrm{Leu}^{2}$. On the fVIIa side, the residues that play a major role in binding to E-76 include $\mathrm{Leu}^{32}, \mathrm{Leu}^{34}, \mathrm{Gln}^{38}, \mathrm{Glu}^{70}$, $\mathrm{His}^{76}, \mathrm{Glu}^{80}$, and $\mathrm{Leu}^{153}$. The authors propose that a large conformational change (approximately $12 \AA$ ) occurs in the 140 s loop of fVIIa, which induces a loss of hydrogen bond between Gln ${ }^{143}$ and Lys ${ }^{192}$. This is significant because residues nearby, i.e., Gly ${ }^{193}$ and $\mathrm{Ser}^{195}$, are involved in forming the oxyanion hole, which may not function appropriately because of the allosteric loop movement.

The discovery of E-76 has led to the identification of several novel peptides, termed the "A-series" peptides, that interact allosterically with fVIIa in a novel manner. $A-183$ has the primary sequence EEWEVLCWTWETCER and contains one disulfide bond [106]. A-183 binds to an allosteric exosite near the active site, which is distinct from the allosteric exosite of E-76. Specifically, the new exosite is composed of the 60s loop and the $C$-terminus with $\operatorname{Trp}^{61}$ and Leu ${ }^{251}$ as the most important residues for binding. In terms of clotting assays, both A-183 and E-76 prolong the PT, and not the APTT, which is typical of fVIIa inhibitors. The $K_{\mathrm{D}}$ for A183 binding to fVII and fVIIa were nearly similar $(\sim 1-3 \mathrm{nM})$, which increased slightly to about $10 \mathrm{nM}$ for their complexes with TF. In a manner similar to E-76, A-183 is specific for fVIIa because no binding was observed for the other nine serine proteases [107]. A-183 potently inhibits $\mathrm{fX}$ and fIX activation by TF-fVIIa complex with $\mathrm{nM} I C_{50}$ values. The maximal inhibition of $\mathrm{fX}$ activation was found to be incomplete $(\sim 78 \%)$, but this feature was considered desirable because it may allow a larger therapeutic window [106]. Finally, the shape and proximity of this exosite to the active site may be favorable for the design of new small molecule anticoagulants that inhibit fVIIa $[95,106,107]$. 


\section{Recombinant Nematode Anticoagulant Protein c2}

Recombinant nematode anticoagulant protein $\mathrm{c} 2$ (rNAPc2) is an 85 -amino acid peptide produced in yeast that binds $\mathrm{fX}$ or $\mathrm{fXa}$ as well as fVIIa and TF-fVIIa complex to inhibit the initiation phase of coagulation. Nematode anticoagulant proteins were discovered following the expectation that haematophagous hookworm parasites would require anticoagulants to maintain the suction of blood from their host. Recently, these peptides were identified and found to function through inhibition of fXa or TF-fVIIa complex [108, 109]. These peptides utilize a unique mechanism in inhibition of the initiation phase. Both natural and rNAPc2 initially bind to an exosite on $\mathrm{fXa}$ to form a proteolytically active $\mathrm{fXa}-\mathrm{rNAPc} 2$ complex. This binary complex then forms a quaternary complex with the TFfVIIa complex through the interaction of the canonical reactive loop of rNAPc2 with active site of fXa. Thus, the overall inhibition of initiation phase by rNAPc2 can be considered as a combination of path ' $a$ ' and ' $d$ ' (Fig. 6).

The bidentate 'bridge-like' interaction of rNAPc2 results in an inhibition constant $\left(\mathrm{K}_{\mathrm{I}}\right)$ of $10 \mathrm{pM}$, primarily arising from a very slow off-rate [109]. Although rNAPc2 binds to fXa, it does not affect its proteolytic activity for small peptidyl substrates [110, 111]. This implies that $\mathrm{fXa}$ in the TF-fVIIa-fXa-rNAPc2 quaternary complex remains active toward small substrates, yet does not cleave macromolecular substrates, e.g., prothrombin, thereby generating the anticoagulant effect.

The crystal structure of the TF-fVIIa-fXa-rNAPc2 quaternary complex is not available as yet, however that for the fXa-NAPc2 binary complex has recently been resolved [112]. From a highly flexible form, NAPc2 undergoes significant structural changes in the $C$-terminus upon binding to the fXa exosite. The binding interface consists of an intermolecular antiparallel $\beta$-sheet formed by residues 74-80 of NAPc 2 with the residues $86-93$ of $\mathrm{fXa}$, which is supported by additional contacts between residues 67-73 and 26-29 of NAPc2 with the short $C$-terminal helix of fXa (residues 233243).

Several clinical trials have been initiated to explore the applicability of rNAPc2 in selected indications, e.g., orthopedic surgery, percutaneous coronary interventions etc. In a recent trial, rNAPc2 did not significantly increase major or minor bleeding and was found to significantly reduce thrombosis $[113,114]$.

\section{SMALL ORGANIC INHIBITORS OF THE INITIATION PHASE}

\section{Covalent Inhibitors}

\section{2-Aryl Substituted Oxazin-4-Ones}

Benzoxazinones have been known as inhibitors of serine proteinases because they irreversibly modify the active site $\operatorname{Ser}^{195}$ residue. Thus, derivatives of the 4H-3,1-benzoxazin-4-one scaffold have been designed to act as inhibitors of $\mathrm{fXa}$ and thrombin. Jakobsen and co-workers report a series of analogs with substitutions on the fused and free aryl rings (Fig. 7) that target the TF-fVIIa complex (Path ' $a$ ', see Fig. 6) [115]. The best inhibitors were those in which the fused aryl ring was substituted with electron withdrawing substituents like $\mathrm{Cl}, \mathrm{NO}_{2}, \mathrm{CF}_{3}$, and $\mathrm{F}$ in the 5,6 , or 7 positions in the oxazine ring together with a 2,6-difluoro substitution in the 2phenyl group. The $I C_{50}$ value for inhibition of factor $\mathrm{X}$ activation by the TF-fVIIa complex was found to span three orders of magnitude with the most potent $I C_{50}$ of $0.2 \mu \mathrm{M}$. Some of the most potent TF-fVIIa inhibitors were also found to inhibit fXa, and to some extent thrombin, although this potency was several orders of magnitude lower. To find better molecules the group investigated heteroaryl oxazin-4-ones (Fig. 7), in which the heteroaryl group was pyrido, pyrazino, pyrimido, pyrazolo, or thieno [116]. The $I C_{50}$ values of these molecules did not improve appreciably.

\section{Non-Covalent Arginine Mimics (Paths 'a' \& 'b') Amidinophenyloxy Substituted Fluoropyridines}

Kohrt and co-workers report the discovery of fluoropyridinebased amidine-containing inhibitors of TF-fVIIa complex. Initially investigated as inhibitors of fXa (high $\mu \mathrm{M} I C_{50}$ ), these molecules were found to inhibit TF-fVIIa with $I C_{50}$ values in the low $\mathrm{nM}$ range, while thrombin activity was in the low $\mu \mathrm{M}$ range $[117,118]$. A reasonably sized library was synthesized of which the best molecule (Fig. 8) had an $I C_{50}$ of $16 \mathrm{nM}$ against TF-fVIIa complex and $2.1 \mu \mathrm{M}$ against thrombin. Fluoropyridines possess a phenyl amidine moiety to recognize $\mathrm{Asp}^{189}$ of fVIIa, while the central fluoropyridine ring orients its two substituents, amino-alkyl and benzoic acid in the S2 pocket and oxy-anion hole, respectively. This results in a characteristic geometry, approximately L-shaped, that recognizes coagulation proteinases.

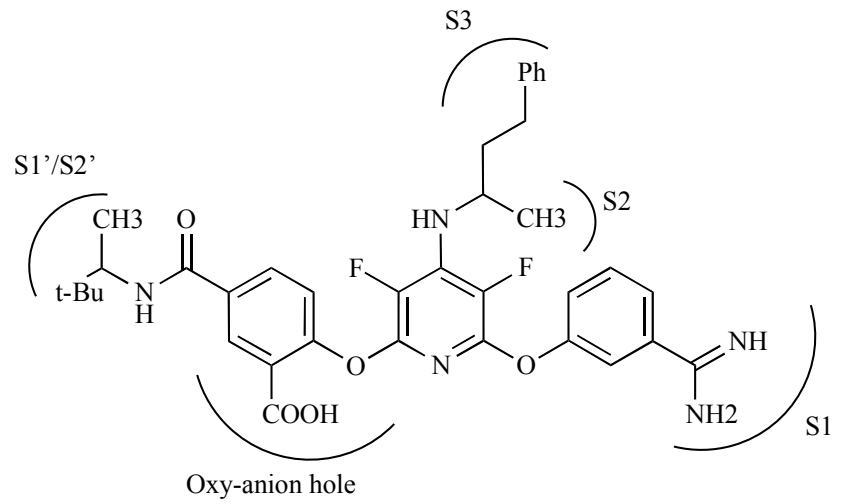

Fig. (8). Structures of amidinophenyloxy substituted fluoropyridines. Of the several analogs investigated, the structure shown is most potent. S1, S2, and S3 represent typical pockets for binding the substrate (inhibitor). S1'/S2' region is a hydrophobic region adjacent to the catalytic triad of fVIIa that the authors exploited in enhancing specificity.

\section{Amidinophenyl Derivatized Phenylglycines}

A group of phenylglycine derivatives have been reported by Zbinden and co-workers that show promising oral bioavailability when used in the double pro-drug form $[119,120]$. Among the sev-

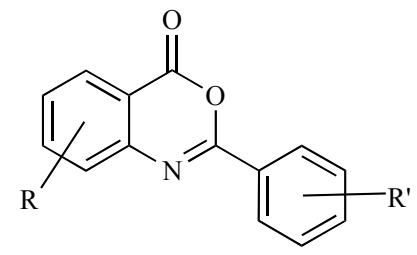

$\mathrm{R}=-\mathrm{Cl},-\mathrm{CH}_{3},-\mathrm{OCH}_{3},-\mathrm{F},-\mathrm{NO}_{2}$ $\mathrm{R}^{\prime}=-\mathrm{H},-\mathrm{CH}_{3},-\mathrm{F}$

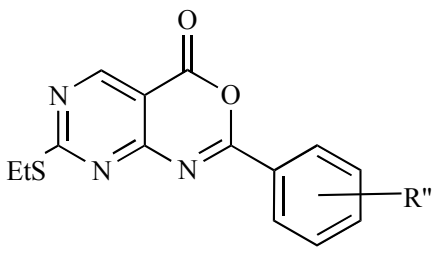

$\mathrm{R}^{\prime \prime}=-\mathrm{NO}_{2},-\mathrm{Cl},-\mathrm{CH}_{3}$<smiles>Cc1csc2nc(-c3ccccc3[N+](=O)[O-])oc(=O)c12</smiles>

Fig. (7). Structures of 2-aryl substituted oxazin-4-ones as inhibitors of TF-fVIIa. R, R' and R” are alkyl, aryl, or electronegative substituents on aromatic rings studied to assess optimal inhibition of TF-fVIIa. The lactone group is cleaved by $\mathrm{Ser}^{195}$ to form acyl-enzyme complex. 
eral substituents introduced on the phenyl ring of Phe, a tetrahydropyranyloxy substituent at the 3 position (inhibitor Pg1, Fig. 9) was found to result in inhibition constant $\left(K_{\mathrm{I}}\right)$ of $81 \mathrm{nM}$ against fVIIa, while inhibition of thrombin, fXa and trypsin was at least 20 -fold weaker for the active form of the drug. X-ray structure analysis of the TF-fVIIa - Pg1 complex showed the characteristic bent shape of the inhibitor at the junction of the two rings so as to maximize the interaction of the $-\mathrm{COOH}$ group with $\mathrm{Lys}^{192}$ and $\mathrm{His}^{57}$, while the hydrophobic tetrahydropyranyloxy ring was found in the S3 pocket. The interaction with Lys ${ }^{192}$ may partly explain the observed higher selectivity for TF-fVIIa. Inhibitor Pg1 also contains a fluorine group on the phenyl ring of the Phe residue, yet it was hypothesized to orient the groups in S2 and S3 pockets rather than making any specific contacts. Finally, the amidoxime/ethyl ester pro-drug form of inhibitor $\mathrm{Pg} 2$ displayed an oral bioavailability of $20 \%$ in rats. More importantly, bleeding propensity studies with one of the analogs of $\underline{\mathrm{Pg} 2}$ suggested that TF-fVIIa inhibition minimally disturbed hemostasis.

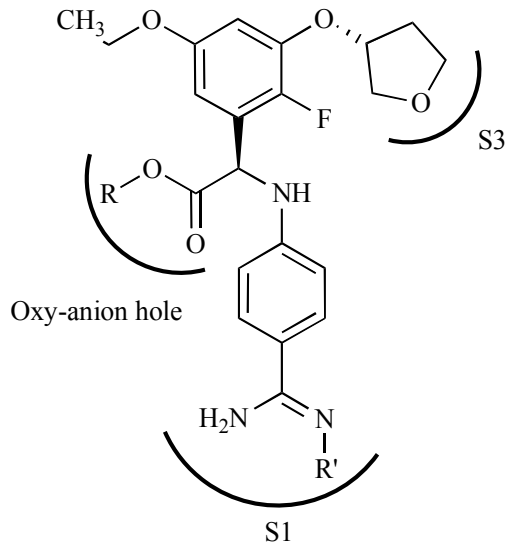

PG1 :: R $=\mathrm{R}^{\prime}=\mathrm{H}$

$\mathrm{PG} 2:: \mathrm{R}=\mathrm{Et}, \mathrm{R}^{\prime}=\mathrm{OH}$

Fig. (9). Structures of amidinophenyl derivatized phenylglycines. The tetrahydropyranyl ring binding in S3 pocket was found to be important for enhancing specificity of action. The prodrug form PG2, i.e., the amidinooxime and carboxyester derivative, of parent inhibitor PG1 was tested in animal model systems.

\section{Amidinophenyl-Containing Pyrazinone Derivatives}

In an excellent structure-based drug design investigation, Parlow et al. [121-126] arrive at pyrazinone derivatives that display very good selectivity for TF-fVIIa. Starting from the crystal structure of a tripeptide ketothiazole KT in complex with TF-fVIIa, the group designed the pyrazinone core scaffold using molecular modeling. A series of pyrazinone analogs were prepared using solidphase synthesis, of which Pz1- and Pz2-based analogs (Fig. 10) were found to better inhibit thrombin than fVIIa. Yet, it was theorized that $\mathrm{Asp}^{60}$ of fVIIa could interact with a proton donor, e.g., $\mathrm{NH}_{2}$, at the $m$-position of the $\mathrm{R}$ substituent. The $\mathrm{x}$-ray crystal structure of $\underline{\mathrm{Pz} 3}$ in complex with fVIIa clearly showed that this hypothesis was true. Likewise, the selectivity of fVIIa also increased nearly 400-fold against thrombin (and 5,000-fold against fXa). To improve this selectivity, inhibitor $\underline{\mathrm{Pz}} 4$ was synthesized. This inhibitor contains a $m$-carboxylic acid group as the $\mathrm{P} 2$ substituent which engages Lys $^{60 \mathrm{~A}}$, thereby increasing the selectivity to 6,250 -fold. On testing in primates, inhibitor $\mathrm{Pz} 4$ was found to prevent thrombosis and have a lower risk of bleeding [127].

Subsequent work exploited a solvent-exposed region outside the $\mathrm{S} 1$ pocket that was possible to reach through ortho substitution of the benzamidine ring in Pz5 (Fig. 11) [128]. This pocket also exists in thrombin, fXa and trypsin, however it contains Lys ${ }^{192}$, which is unique to fVIIa. Several substituents were introduced and each found to display nanomolar $I C_{50}$ against TF-fVIIa and moderate selectivity.

\section{Amidine Containing Substituted Pyridones, Benzenes, and Ben- zoquinones}

The pyrazinone scaffold contains two nitrogens in the central ring and it was not clear whether this structure is critical for potency and selectivity. To assess the importance of the pyrazinone structure, each nitrogen was sequentially eliminated to generated substituted pyridones, benzenes and benzoquinones [129, 130]. Replacement of the nitrogen at the 4 position of pyrazinone scaffold gave the pyridone scaffold [130], which exhibits reasonable potency against fVIIa $\left(I C_{50}=118 \mathrm{nM}\right)$, yet it was weaker than that for the pyrazinone structure probably due to loss of $\mathrm{H}$-bonding and van der Waals interactions. Further studies led to the development of inhibitor $\underline{\mathrm{Pd}}$ with $52 \mathrm{nM} I C_{50}$ against TF/FVIIa and $>700$ fold selectivity over thrombin and fXa [130]. Replacing the remaining nitrogen atom gave the substituted benzenes $\mathrm{Bz}$, which were oxidized to benzoquinones $\mathrm{Bq}$ (Fig. 12). Both these new scaffolds exhibited good potency $(<10 \mathrm{nM})$ for TF-fVIIa and good selectivity $(\sim 3,000-$ fold) over thrombin [131]. It is important to note that the benzene or benzoquinone derivatives do not contain an $-\mathrm{NH}_{2}$ group, equivalent to the $-\mathrm{NH}_{2}$ on the pyrazinone and pyridone structures, which was known to interact favorably with Asp ${ }^{60}$.

\section{Amidinobenzimidazoles}

Starting from amidino-benzimidazole scaffold $\mathrm{Bm} 1$, which displayed 2,800-fold selectivity of fVIIa over thrombin, but poor selectivity over fXa and trypsin, Shrader et al. describe the design of inhibitors $\mathrm{Bm} 2-\mathrm{Bm} 6$, which shows $>12,000-, 500$ - and 1,000fold selectivity of fVIIa over thrombin, fXa and trypsin [132] (Fig. 13). They propose that fVIIa contains a unique $G \ln ^{143}$ residue that hydrogen bonds to $\mathrm{Gln}^{193}$, which induces rotation of Lys ${ }^{192}$ side chain in the oxy-anion hole, thereby allowing the formation of specific ionic bonds with inhibitors $\mathrm{Bm} 2-\mathrm{Bm} 6$. In addition to the significant enzyme specificity, the inhibitors possess high water solubility as well as an excellent parenteral pharmacokinetic profile.

\section{Naphthylamidines}

In an effort to simplify the structure of TF-fVIIa inhibitors, Buckman et al. [133] synthesized a small library of naphthylamidines (Fig. 14) using solid-phase synthesis. The majority of molecules displayed reasonable $K_{\mathrm{I}}$ for TF-fVIIa; however, their selectivity against thrombin, fXa and trypsin was not impressive (1-10-fold).

\section{Amidinophenylpyruvic Acid Analogs}

Sagi et al. [134] describe an interesting approach of inducing a stable, covalent tetrahedral, but reversible, intermediate as a means of specific recognition. Upon screening a library of fXa inhibitors, the group discovered potent TF-fVIIa activity arising from pyruvic acid derivatives of the type of Pa1 (Fig. 15). They hypothesized that this activity possibly originates from the formation of a tetrahedral intermediate by the attack of $\mathrm{O} \gamma$ of $\mathrm{Ser}^{195}$ on the carbonyl carbon of pyruvic acid. Docking studies revealed that it may be possible to achieve higher selectivity for TF-fVIIa by introducing a Rcarboxyethyl group at the R2 position and replacing the 4guanidinophenyl group at the R1 position with torsion angle restricted analogs. Several analogs were prepared, of which $\mathrm{Pa} 2$ (Fig 15) containing a benzothiazole group was found to have a $K_{\mathrm{I}}$ of 1 $\mathrm{nM}$ against TF-fVIIa and, 1800- and 150,000-fold selectivity over fXa and thrombin, respectively.

\section{Peptidomimetic Amidines}

Kadono and co-workers report the investigation of a series of peptidomimetic structures starting from an initial lead structure Pm1 that exhibited good potency for TF-fVIIa and reasonable 


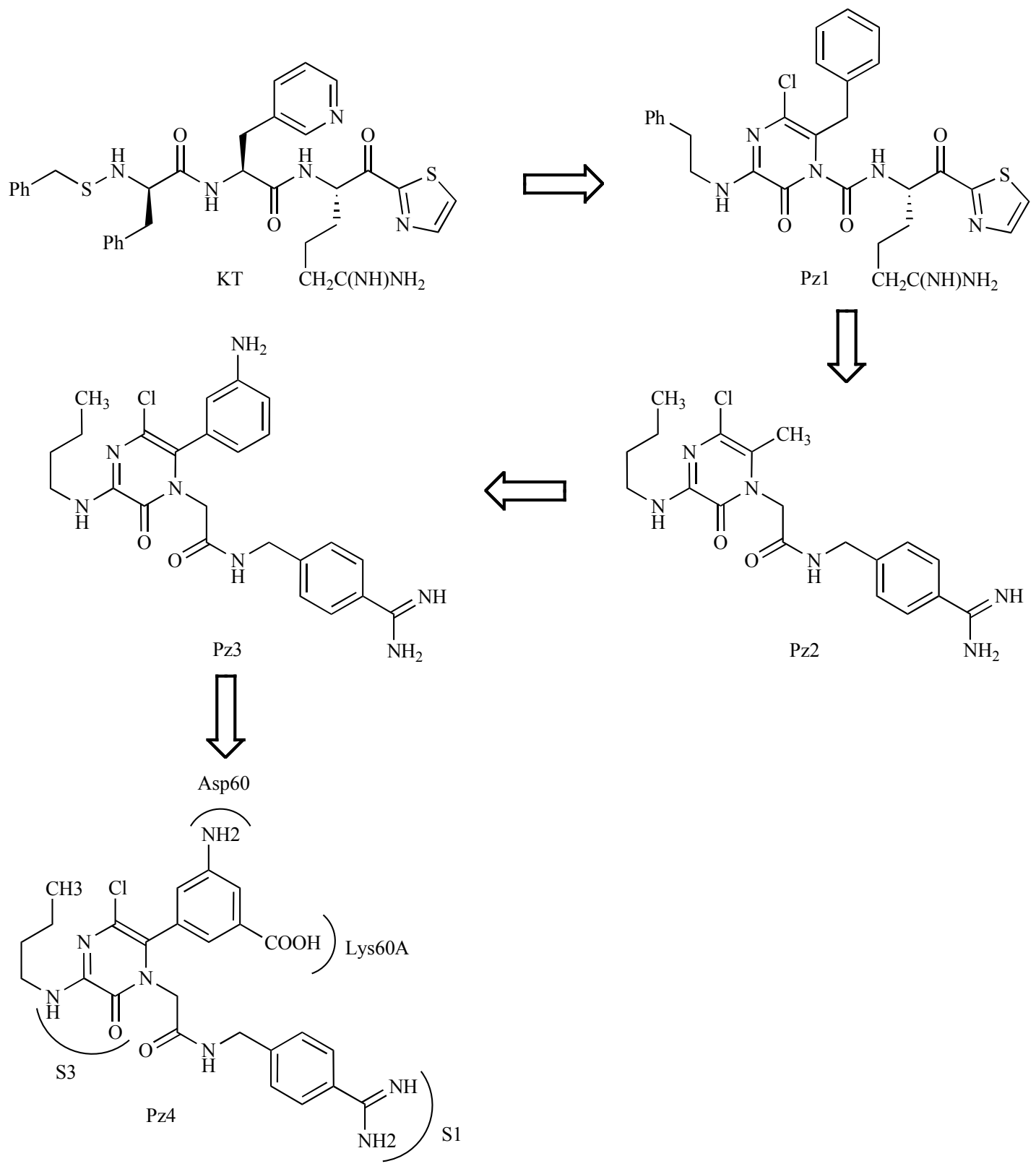

Fig. (10). Structures of amidinophenyl-containing pyrazinone derivatives. A series of publications from Celera describe the structure-based design of pyrazinone analogs $(\underline{\mathrm{Pz}})$ that show good specificity of fVIIa inhibition. A key feature in this design is the engineering of groups that recognize Asp ${ }^{60}$ and Lys ${ }^{60 \mathrm{~A}}$ of fVIIa, which is likely the origin of specificity.

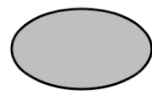<smiles>[R]c1cc(C(=N)N)ccc1CNC(=O)Cn1c(-c2cccc(C(=O)N[C@@H](C)CC)c2)c(Cl)nc(NC(C)C)c1=O</smiles>

$\mathrm{R}=$<smiles>CC(N)=O</smiles><smiles>CC(=O)Nc1ccncc1</smiles><smiles>CC(=O)NCCN1CCOCC1</smiles>

Fig. (11). Structures of additional amidinophenyl-containing pyrazinone derivatives. Of the numerous groups investigated at the R position, the amide derivatives (shown on right) were most effective in enhancing specificity for fVIIa. 
<smiles>CC(C)Nc1ccc(-c2cc(N)cc(N)c2)n(CC(=O)NCc2ccc(C(=N)N)cc2)c1=O</smiles><smiles>[R]Nc1ccc(-c2cccc([R])c2)c(CC(=O)NCc2ccc(C(=N)N)cc2)c1[R2]</smiles><smiles>CC(C)NC1=CC(=O)C(c2ccccc2)=C(CC(=O)NCc2ccc(C(=N)N)cc2)C1=O</smiles>

Fig. (12). Structures of amidine containing substituted pyridones, benzenes, and benzoquinones. The pyrazinone scaffold of Figs. 15 and 16 was replaced with pyridone, benzene and benzoquinone rings, yet the molecules were sufficiently active.

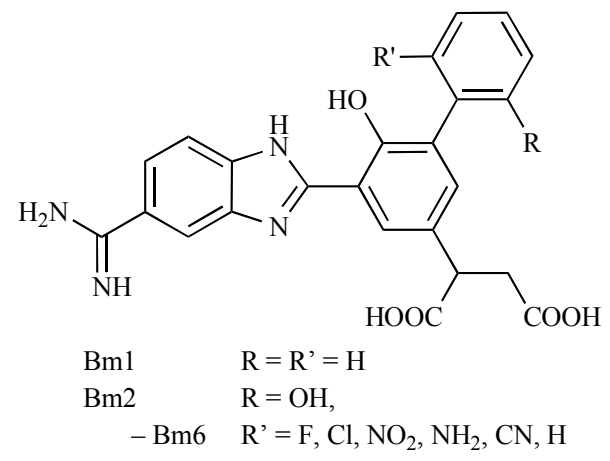

Fig. (13). Structures of amidinobenzimidazoles. Structurally these are one of the simplest fVIIa inhibitors that show reasonable specificity of action.

selectivity against thrombin (26-fold) [135-137]. Introducing sequential changes in the P2 and P3 moieties of inhibitor Pm1 increased the TF-fVIIa potency nearly 2.5 -fold but decreased the $I C_{50}$ value of thrombin inhibition nearly 4 -fold, thus increasing selectivity to $\sim 260$-fold (Fig. 16). Factor Xa or trypsin selectivity was not assessed.

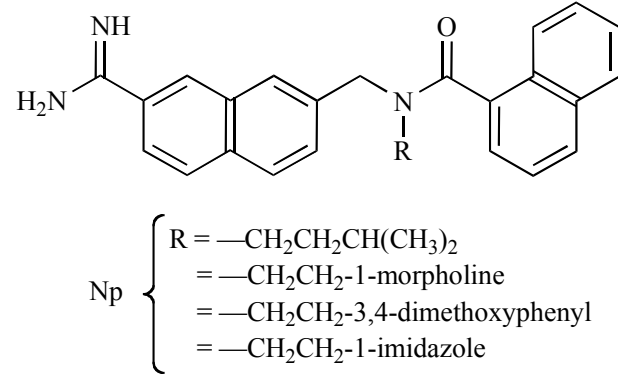

Fig. (14). Structures of naphthylamidines. Structurally these are one of the simplest fVIIa inhibitors that show reasonable specificity of action.

\section{Amidinophenylureas}

Klinger and colleagues have designed amidinophenylureas (Fig. 17) in which the urea moiety is involved in recognition of the Ser ${ }^{195}$ residue in addition to the salt bridge formation between amidino moiety and $\mathrm{Asp}^{189}$. Their rational design relied on finding a hydrophobic group that interacts well with the face formed by $\operatorname{Trp}^{215}$. Some of the best substituents were found to be aromatic groups that likely stack well with $\operatorname{Trp}^{215}$ and its hydrophobic environment. In addition, some aromatic substituents also stacked well with $\mathrm{His}^{57}$, thus generating considerable potency and selectivity. The best inhibitors (Fig. 17) had TF-fVIIa inhibition constant of $\sim 25 \mathrm{nM}$ and a selectivity against fXa and thrombin of $>370$ - and $>3700$-fold, respectively $[138,139]$.

\section{Non-Covalent Non-Arginine Mimics (Paths ' $a$ ' \& 'b') Carboxylic Acid Substituted p,p'-Biphenyl Amines}

Miura et al. report the discovery of TF-fVIIa inhibitors with neutral P1 moieties starting from amidine-containing biphenyl lead

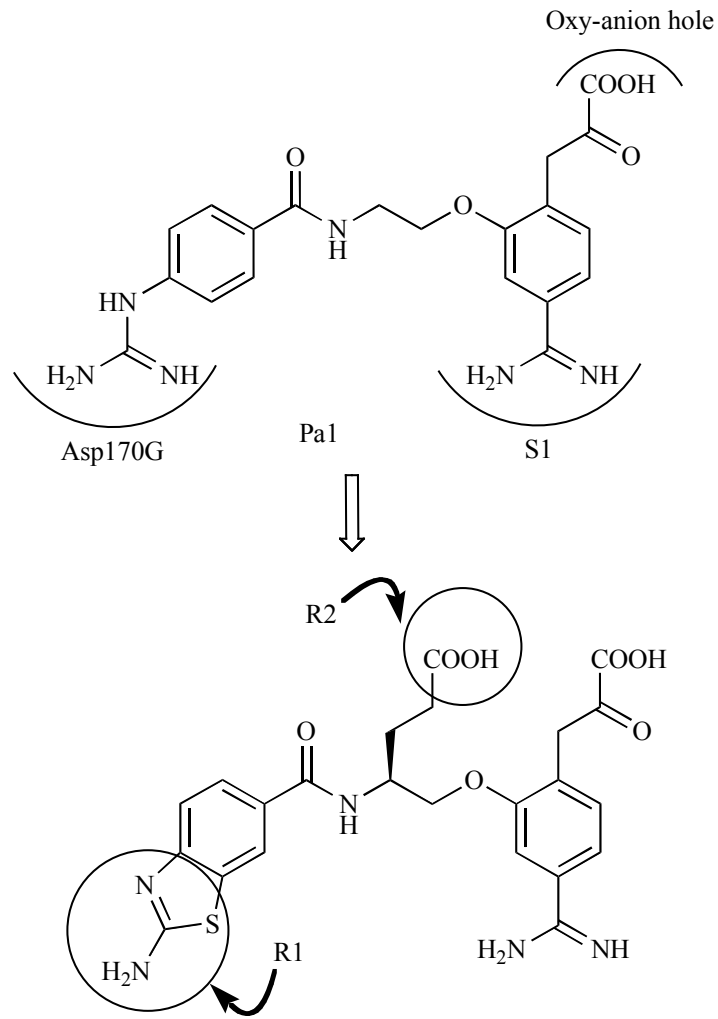

Fig. (15). Structures of amidinophenylpyruvic acid analogs. These fVIIa inhibitors consist of interesting groups, e.g., acidic and basic groups. 


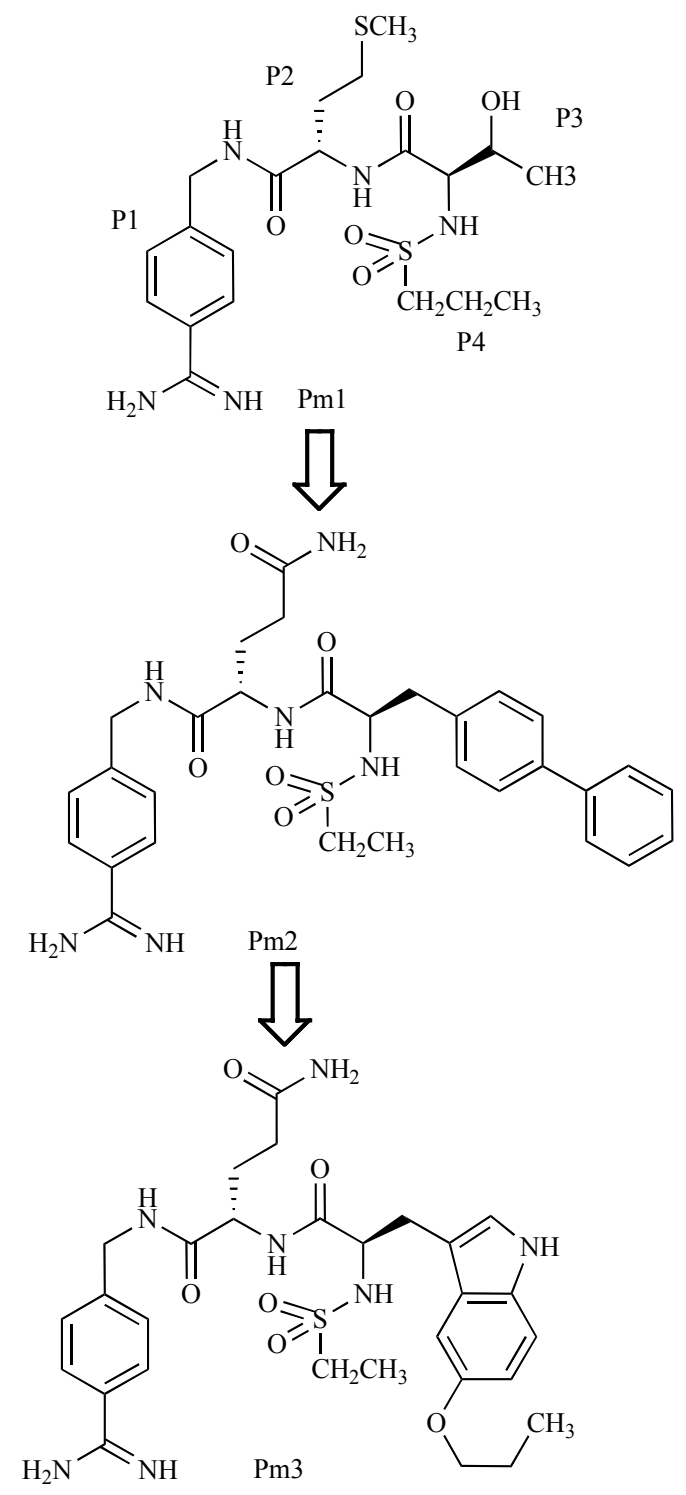

Fig. (16). Structures of peptidomimetic amidines as inhibitors of fVIIa. These inhibitors are effectively tetrapeptides consisting of P1 through P4 'residues'.

compound [140]. Several electron withdrawing and donating substituents were investigated on the core biphenyl scaffold to arrive at the most potent molecule Bp (Fig. 18) with an $I C_{50}$ of $690 \mathrm{nM}$ against TF-fVIIa and $>200 \underline{\mu \mathrm{M}}$ against $\mathrm{fXa}$, thrombin and trypsin. Inhibitor $\mathrm{Bp}$ contained a $t$-butylaminocarbonyl group, which was predicted to bind to $\mathrm{Ser}^{190}$ residue in fVIIa thereby generating affinity for fVIIa in comparison to that for fXa. Molecular modeling suggested that the overall conformation of these molecules was more suitable for interaction with residues of the S2 pocket in fVIIa compared to other enzymes.

The above work has recently been extended through analogs of $N$-isobutyl and $N$-methyl groups (R and R' in Fig. 18, above) [141]. The primary reason for screening these variations was the observation that the $i$-Bu group was probably oriented in the site consisting of Lys ${ }^{192}$. Several analogs were screened to find that a molecule with a carboxylic acid containing i-Bu group was the best of the series. Screening several R' groups showed that the $N$-methyl group was the best. Finally, inhibitor $\underline{B p}$ was tested in monkeys and found to increase the PT, while not altering APTT. Importantly, bleeding

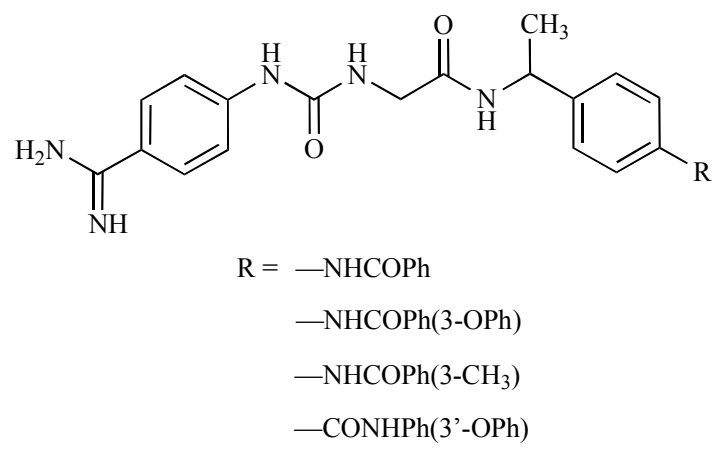

Fig. (17). Structures of amidinophenyl ureas. The structures of these ureabased inhibitors bear resemblance to napthylamidines (Fig. 17), especially with respect to placement of amidine moiety and arrangement of aromatic rings at either end of the inhibitors.

time never increased over the baseline at the highest dose level of $30 \mathrm{mg} / \mathrm{kg}$ studied.

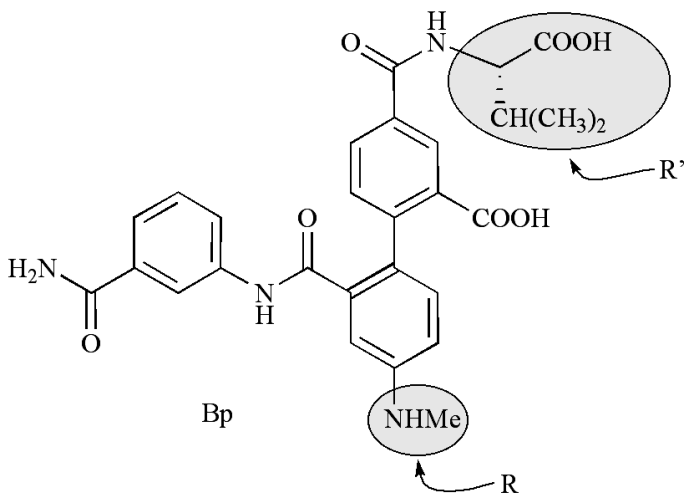

Fig. (18). Structures of $p, p^{\prime}$-biphenyl amines. Several R and R' groups were investigated, of which the groups shown above were found to be most promising.

\section{Aza-Indoles}

In an effort spanning several years and publications, Celera scientists describe the discovery of the electroneutral P1 moiety 4amino-5-azaindole as an amidino-benzimidazole mimic. Starting with an amidine derivative Ail (Fig. 19), which displayed a $K_{\mathrm{I}}$ of $13 \mathrm{nM}$ against TF-fVIIa complex and greater than 200-fold selectivity versus $\mathrm{fXa}$, thrombin and trypsin, the group explored several structural scaffolds including 5-azaindoles [142-145]. The 5azaindole moiety is likely to be partially protonated at $\mathrm{pH} 7.4$ (calculated $\mathrm{p} K_{\mathrm{A}} \sim 7.9$ ) resulting in good recognition of $\mathrm{Asp}^{189}$ and concomitantly high binding affinity. Introducing 4-amino substitution on the 5-azaindole ring was thought to enhance the proportion of protonated species (calculated $\mathrm{p} K_{\mathrm{A}} \sim 9.9$ ), thus resulting in even better recognition [146]. In fact, inhibitor Ai3 containing the carboxylate group, which most probably binds to Lys ${ }^{192}$, and the difluorophenylurea group, which probably engages Lys ${ }^{60 \mathrm{~A}}$ and $\mathrm{His}^{57}$, displayed a $K_{\mathrm{I}}$ of $2.6 \mathrm{nM}$ against TF-fVIIa, while displaying nearly 10,000 -fold poor affinity for thrombin, fXa and trypsin.

\section{Natural Products Inhibitors of fVIIa (Paths 'a' \& 'b')}

\section{Dysinosin A}

An interesting new marine natural product, dysinosin A (Fig. 20), from a new sponge family Dysideidae was isolated recently [147]. Dysinosin A is a potent inhibitor of the fVIIa. Dysinosin A contains a 5,6-dihydroxyoctahydroindole-2-carboxylic acid scaffold. In addition, it contains pyrroline ring with substitution that 
<smiles>N=C(N)c1ccc2[nH]c(-c3c(O)cccc3-c3ccc(CNC(N)=O)cc3O)nc2c1</smiles>

Ail

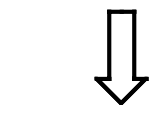<smiles>O=C(NCc1ccc(-c2cccc(O)c2-c2cc3cnccc3[nH]2)c(O)c1)C(O)Cc1ccccc1</smiles>

Ai2

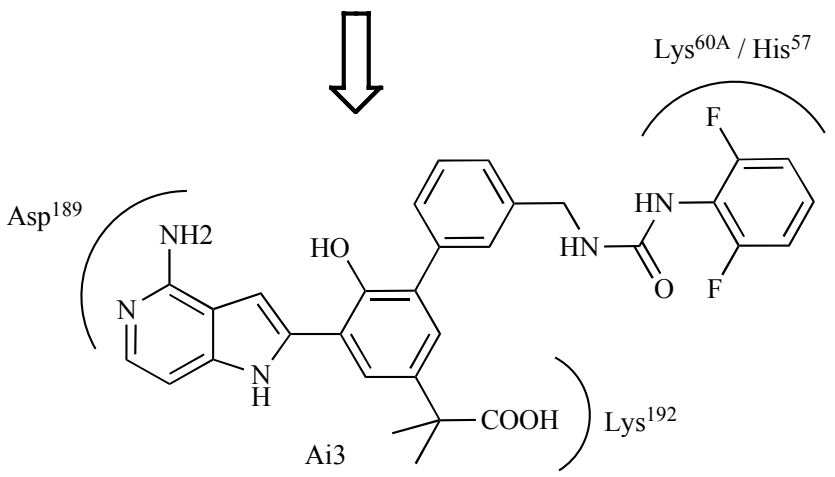

Fig. (19). Structures of aza-indole based fVIIa inhibitors. Aza-indoles were derived from amidine-containing indoles Ail, which were modified to 4amino aza-indole because of the possibility of mimicking the amidine group. The structure-based design resulted in engineering of interaction with Lys ${ }^{192}$ and $\mathrm{Lys}^{60 \mathrm{~A}} / \mathrm{His}^{57}$ residues.

mimics an arginine side chain, and a sulfated glyceric acid. Dysinosin A inhibits fVIIa with a $K_{\mathrm{I}}$ of $108 \mathrm{nM}$, however it is not specific because it also inhibits thrombin with $452 \mathrm{nM}$ affinity. The total synthesis of dysinosin A has been achieved [148] and it is to be expected that this will ease the synthesis of analogs for structureactivity relationship studies. Likewise, dysinosins B - D have been isolated and found to be inhibitors of fVIIa [149].

\section{CONCLUSIONS}

Several structural scaffolds in the small organic inhibitor class exhibit promising fVIIa activity. In addition, a few of the inhibitors<smiles>[R]C12C[C@H](O)[C@@H](O)C[C@H]1C[C@@H](C(=O)NCCC1=CCN(C(=N)N)C1)N2C(=O)[C@H](CC(C)C)NC(=O)[C@H](CO[C+]([O-])([O-])[O-])OC</smiles>

Fig. (20). Structure of dysinosin A. Dysinosin A is a natural product isolated from a new sponge family Dysideidae and is a potent inhibitor of fVIIa and thrombin.

display good specificity for fVIIa in comparison to thrombin and fXa, while selectivity against trypsin may require further improvement. It is likely that many more organic scaffolds exist, and may be discovered, that will display better activity and specificity. Structure-based drug design, especially focusing on $\mathrm{Asp}^{60}$, Lys ${ }^{60 \mathrm{~A}}$, and Lys ${ }^{192}$, is likely to guide this discovery. The examples discussed here highlight the relatively rewarding experience with fVIIa.

A key question however is whether inhibiting the initiation phase will provide the benefit of significantly reduced bleeding complications. The study with rTFPI indicates that this may not be feasible, while the studies with small organic inhibitors point in a more favorable direction. It is possible that high potency, e.g, as of rTFPI, is a limitation with respect to bleeding, rather than an advantage. It should also be pointed out that the current designs almost exclusively target paths ' $a$ ' and ' $b$ ' (Fig. 6), while several other mechanistic possibilities exist. As our understanding of these possibilities increases, so will the repertoire of possible inhibitors. Overall, success with the approach of selectively inhibiting the initiation phase appears to be more feasible with small highly specific organic inhibitors.

\section{ACKNOWLEDGEMENTS}

The authors thank Professor Tonie Wright and Mr. Arjun Raghuraman of Virginia Commonwealth University for their critical reading of the manuscript. This work was supported in part by the National Heart, Lung and Blood Institute (RO1 HL069975 and R41 HL081972), the American Heart Association National Center (EIA 0640053N) and the A. D. Williams Foundation (6-48708).

\section{REFERENCES}

[1] Macfarlane, R.G. Nature, 1964, 202, 498

[2] Davie, E.W.; Ratnoff, O.D. Science, 1964, 145, 1310

[3] Hoffman, M.; Monroe, D.M., 3rd. Thromb. Haemost., 2001, 85, 958.

[4] Hoffman; M. Blood Rev., 2003, 17, S1.

[5] Monroe, D.M.; Hoffman, M. Arterioscler. Thromb. Vasc. Biol., 2005, $26,41$.

[6] Østerud, B.; Bjørklid, E. Semin. Thromb. Hemost., 2006, 32, 11.

[7] Rao, L.V.; Rapaport, S.I. Proc. Natl. Acad. Sci., 1988, 85, 6687.

[8] Neuenschwander, P.F.; Fiore, M.M.; Morrissey, J.H. J. Biol. Chem., 1993, $268,21489$.

[9] Kirchhofer, D.; Eigenbrot, C.; Lipari, M.T.; Moran, P.; Peek, M.; Kelley, R.F. Biochemistry, 2001, 40, 675.

[10] Lawson, J.H.; Mann, K.G. J. Biol. Chem., 1991, 266, 11317.

[11] Hoffman, M.; Monroe, D.M.; Oliver, J.A.; Roberts, H.R. Blood, 1995, 86 , 1794.

[12] Monroe, D.M.; Hoffman, M.; Roberts, H.R. Blood Coagul. Fibrinolysis, 1996, 7, 459 .

[13] Orfeo, T.; Brufatto, N.; Nesheim, M.E.; Xu, H.; Butenas, S.; Mann, K.G. J. Biol. Chem., 2004, 279, 19580.

[14] Lollar, P.; Knutson, G.J.; Fass, D.N. Biochemistry, 1985, 24, 8056.

[15] Bukys, M.A.; Orban, T.; Kim, P.Y.; Beck, D.O.; Nesheim, M.E.; Kalafatis, M. J. Biol. Chem., 2006, 281, 18569.

[16] Wielders, S.J.; Béguin, S.; Hemker, H.C.; Lindhout, T. Arterioscler. Thromb Vasc. Biol., 2004, 24, 1138.

[17] Pedicord, D.L.; Seiffert, D; Blat, Y. Proc. Natl. Acad. Sci., 2007, 104, 12855.

[18] Standeven, K.F.; Ariëns, R.A.; Grant, P.J. Blood Rev., 2005, 19, 275. 
[19] Roberts, H.R.; Hoffman, M.; Monroe, D.M. Semin. Thromb. Hemost., 2006, 32(Suppl. 1), 32.

[20] Mosesson, M.W. J. Thromb. Haemost., 2005, 3, 1894

[21] Mosesson, M.W.; Siebenlist, K.R.; Meh, D.A. Ann. N. Y. Acad. Sci. 2001, 936, 11.

[22] Bjork, I.; Olson, S.T. Adv. Exp. Med. Biol., 1997, 425, 17.

[23] Griffin, J.H.; Fernandez, J.A.; Gale, A.J.; Mosnier, L.O. J. Thromb. Haemost., 2007, 5(Suppl. 1), 73.

[24] Crawley, J.T.; Lane, D.A. Arterioscler. Thromb. Vasc. Biol., 2008, 28(2), 233.

[25] Olson, S.T.; Swanson, R.; Raub-Segall, E.; Bedsted, T.; Sadri, M.; Petitou, M.; Herault, J.P.; Herbert, J.M.; Bjork, I. Thromb Haemost., 2004, 92, 929.

[26] Larsen, K.S.; Ostergaard, H.; Bjelke, J.R.; Olsen, O.H.; Rasmussen, H.B.; Christensen, L.; Kragelund, B.B.; Stennicke, H.R. Biochem. J., 2007, 405, 429.

[27] Zhao, M.; Abdel-Razek, T.; Sun, M.; Gailani, D. J. Biol. Chem., 1998, 273, 31153 .

[28] Desai, U.R. Med.Res. Rev., 2004, 24, 151

[29] Cushman, M.; Tsai, A.W.; White, R.H.; Heckbert, S.R.; Rosamond, W.D.; Enright, P.; Folsom, A.R. Am. J. Med., 2004, 117, 19.

[30] Lopez, J.A.; Kearon, C.; Lee, A.Y. Hematology Am. Soc. Hematol. Educ. Program. 2004, 439.

[31] Mousa, S.A. Drugs Today (Barc.)., 2006, 42, 331

[32] Murray, C.J.; Lopez, A.D. Lancet, 1997, 349, 1269

[33] McLean, J. Am. J. Physiol., 1916, 41, 250.

[34] Campbell, H.A.; Link, K.P. J. Biol. Chem., 1941, 138, 21.

[35] Hirsh, J.; Anand, S.S.; Halperin, J.L.; Fuster, V. Circulation, 2001, 103, 2994.

[36] Hogg, P.J.; Jackson, C.M. Proc. Natl. Acad. Sci. USA, 1989, 86, 3619.

[37] Weitz, J.I.; Hudoba, M.; Massel, D.; Maraganore, J.; Hirsh, J. J. Clin. Invest., $\mathbf{1 9 9 0}, 86,385$.

[38] Meddahi, S.; Bara, L.; Fessi, H.; Samama, M.M. Blood Coagul. Fibrinolysis, 2000, 11,51 .

[39] Kumar, R.; Beguin, S.; Hemker, H.C. Thromb. Haemost., 1994, 72, 713

[40] Antman, E.M.; Morrow, D.A.; McCabe, C.H.; Murphy, S.A.; Ruda, M.; Sadowski, Z.; Budaj, A.; Lopez-Sendon, J.L.; Guneri, S.; Jiang, F.; White, H.D.; Fox, K.A.; Braunwald, E. New Eng. J. Med., 2006, 354, 1477.

[41] Senaran, H.; Acaroglu, E.; Ozdemir, H.M.; Atilla, B. Arch. Orthop. Trauma Surg., 2006, 126, 1.

[42] Thorevska, N.; Amoateng-Adjepong, Y.; Sabahi, R.; Schiopescu, I.; Salloum, A.; Muralidharan, V.; Manthous, C.A. Chest, 2004, 125, 856.

[43] Fanikos, J.; Tsilimingras, K.; Kucher, N.; Rosen, A.B.; Hieblinger, M.D.; Goldhaber, S.Z. Am. J. Cardiol., 2004, 93, 247.

[44] Holzheimer, R.G. Eur. J. Med. Rev., 2004, 9, 225.

[45] Yusuf, S.; Mehta, S.R.; Chrolavicius, S.; Afzal, R.; Pogue, J.; Granger, C.B.; Budaj, A.; Peters, R.J.; Bassand, J.P.; Wallentin, L.; Joyner, C.; Fox, K.A. New Eng. J. Med., 2006, 354, 1464.

[46] Chung, T.L.; Holton, L.H., $3^{\text {rd }}$; Silverman, R.P. Ann. Plast. Surg., 2006, 56, 312 .

[47] Samama, M.M.; Gerotziafas, G.T. Thromb. Res., 2003, 109, 1

[48] Turpie, A.G.; Eriksson, B.I.; Lassen, M.R.; Bauer, K.A. Curr. Opin. Hematol., 2003, 10, 327

[49] Gallus, A.S.; Coghlan, D.W. Curr. Opin. Hematol., 2002, 9, 422.

[50] Petitou, M.; van Boeckel, C.A. Angew. Chem. Int. Ed. Engl., 2004, 43, 3118.

[51] de Kort, M.; Buijsman, R.C.; van Boeckel, C.A. Drug Discov. Today, 2005, 10,769 .

[52] Walenga, J.M.; Jeske, W.P.; Fareed, J. Expert Opin. Investig. Drugs, 2005, $14,847$.

[53] Gerotziafas, G.T.; Samama, M.M. Curr. Pharm. Des., 2005, 11, 3855

[54] Herbert, J.M.; Herault, J.P.; Bernat, A.; van Amsterdam, R.G.; Lormeau, J.C.; Petitou, M.; van Boeckel, C.; Hoffmann, P.; Meuleman, D.G. Blood, 1998, 91, 4197.

[55] Schwienhorst, A. Cell. Mol. Life Sci., 2006, 63, 2773.

[56] Klauss, V.; Spannagl, M. Curr. Drug Targets, 2006, 7, 1285.

[57] Ieko, M.; Tarumi, T.; Nakabayashi, T.; Yoshida, M.; Naito, S.; Koike, T. Front. Biosci., 2006, 11, 232.

[58] Bauer, K.A. Hematology Am. Soc. Hematol. Educ. Program, 2006, 450

[59] Agnelli, G. Pathophysiol. Haemost. Thromb., 2005, 34(Suppl. 1), 2

[60] Hirsh, J.; O'Donnell, M.; Weitz, J.I. Blood, 2005, 105, 453.

[61] Becker, R.C.; Alexander, J.; Dyke, C.K.; Harrington, R.A. Thromb. Haemost., 2004, 92, 1182.

[62] Kikelj, D. Pathophysiol. Haemost. Thromb., 2003, 33, 487

[63] Weitz, J.I.; Hudoba, M.; Massel, D.; Maraganore, J.; Hirsh, J. J. Clin. Invest., $\mathbf{1 9 9 0}, 86,385$.

[64] Weitz, J.I.; Leslie, B.; Hudoba, M. Circulation, 1998, 97, 544

[65] Berry, C.N.; Girardot, C.; Lecoffre, C. Thromb. Haemost., 1994, 72, 381.

[66] Taniuchi, Y.; Sakai, Y.; Hisamichi, N.; Kayama, M.; Mano, Y.; Sato, K.; Hirayama, F.; Koshio, H.; Matsumoto, Y.; Kawasaki, T. Thromb. Haemost., 1998, 79, 543

[67] Mohapatra, R.; Tran, M.; Gore, J.M.; Spencer, F.A. Am. Heart J., 2005, 150, 19.

[68] Stempelj, M.; Zorko, M.; Peternel, L.; Urleb, U.; Ferjan, I. Eur. J. Pharmacol., 2006, 538,182 .
[69] Peternel, L.; Stempelj, M.; Cerne, M.; Zega, A.; Obreza, A.; Oblak, M.; Drevensek, G.; Budihna, M.V.; Stanovnik, L.; Urleb, U. Thromb. Haemost., 2006, 95, 294.

[70] Moreno, P.R. J. Stroke Cerebrovasc. Dis., 2001, $10(2 \mathrm{Pt} 2), 2$.

[71] Vojacek, J.; Dusek, J.; Bis, J.; Stasek, J.; Blazek, M. Physiol. Res., 2008 (in press).

[72] Girard, T.J.; Nicholson, N.S. Curr. Opin. Pharmacol., 2001, 1, 159.

[73] Harker, L.A.; Hanson, S.R.; Wilcox, J.N.; Kelly, A.B. Haemostasis, 1996, 26(Suppl. 1), 76.

[74] Butenas S.; Ribarik, N.; Mann, K.G. Biochemistry, 1993, 32, 6531.

[75] Butenas, S.; Mann, K.G. Biochemistry, 1996, 35, 1904

[76] Higashi, S.; Nishimura, H.; Fujii, S.; Takada, K.; Iwanaga, S. J. Biol. Chem., 1992, 267, 17990 .

[77] Neuenschwander, P.F.; Branam, D.; Morrissey, J.H. Thromb. Haemost. 1993, 70, 970 .

[78] Eigenbrot, C.; Kirchhofer, D.; Dennis, M.S.; Santell, L.; Lazarus, R.A.; Stamos, J.; Ultsch, M.H. Structure, 2001, 9, 627.

[79] Banner, D.W.; D'Arcy, A.; Chène, C.; Winkler, F.K.; Guha, A.; Konigsberg, W.H.; Nemerson, Y.; Kirchhofer, D. Nature, 1996, 380, 41.

[80] Zhang, E. St.; Charles, R.; Tulinsky, A. J. Mol. Biol., 1999, 285, 2089.

[81] Zhong, D.; Smith, K.J.; Birktoft, J.J.; Bajaj, S.P. Proc. Natl. Acad. Sci., 1994, 91, 3574 .

[82] Roy, S.; Hass, P.E.; Bourell, J.H.; Henzel, W.J.; Vehar, G.A. J. Biol. Chem., 1991, 266, 22063.

[83] Ruf, W.; Miles, D.J.; Rehemtulla, A.; Edgington, T.S. J. Biol. Chem., 1992, 267,6375 .

[84] Kirchhofer, D.; Lipari, M.T.; Moran, P.; Eigenbrot, C.; Kelley, R.F. Biochemistry, 2000, 39, 7380 .

[85] Zhong, D.; Bajaj, M.S.; Schmidt, A.E.; Bajaj, S.P. J. Biol. Chem., 2002, 277, 3622 .

[86] Ndonwi, M.; Broze, G.J.; Bajaj, S.P. J. Thromb. Haemost., 2005, 3, 112.

[87] Ndonwi, M.; Broze, G.J. Jr.; Agah S.; Schmidt, A.E.; Bajaj, S.P. J. Biol. Chem., 2007, 282, 15632.

[88] Manithody, C.; Yang, L.; Rezaie, A.R. Biochemistry, 2007, 46, 3193.

[89] Wu, P.C.; Hamaguchi, N.; Yu, Y.S.; Shen, M.C.; Lin, S.W. Thromb. Haemost., 2000, 84, 626 .

[90] Chen, S-W.; Pellequer, J-L.; Schved, J-F.; Giansily-Blaizot, M. Thromb Haemost., 2002, 88, 74 .

[91] Norledge, B.V.; Petrovan, R.J.; Ruf, W.; Olson, A.J. Proteins, 2003, 53, 640.

[92] Ashton, A.W.; Boehm, M.K.; Johnson, D.J.; Kemball-Cook, G.; Perkins, S.J. Biochemistry, 1998, 37, 8208.

[93] Pike, A.C.; Brzozowski, A.M.; Roberts, S.M.; Olsen, O.H.; Persson, E. Proc. Natl. Acad. Sci. USA, 1999, 96, 8925.

[94] Sichler, K.; Banner, D.W.; D'Arcy, A.; Hopfner, K.P.; Huber, R.; Bode, W.; Kresse, G.B.; Kopetzki, E.; Brandstetter, H. J. Mol. Biol., 2002, 322, 591.

[95] Eigenbrot, C.; Kirchhofer, D.; Dennis, M.S.; Santell, L.; Lazarus, R.A.; Stamos, J.; Ultsch, M.H. Structure, 2001, 9, 627.

[96] Kemball-Cook, G.; Johnson, D.J.; Tuddenham, E.G.; Harlos, K. J. Struct. Biol., 1999, 127, 213.

[97] Bajaj, S.P.; Schmidt, A.E.; Agah, S.; Bajaj, M.S.; Padmanabhan, K. J. Biol. Chem., 2006, 281, 24873.

[98] Rezaie, A.R. J. Biol. Chem., 1996, 271, 23807.

[99] Rezaie, A.R. Biochemistry, 1997, 36, 7437.

[100] Ruf, W. Blood Coagul. Fibrinolysis, 1998, 9(Suppl. 1), S73.

[101] Matyal, R.; Mahmood, F.; Park, K.W. Int. Anesthesiol. Clin., 2005, 43, 135.

[102] Linkins, L.A.; Weitz, J.I. Annu. Rev. Med., 2005, 56, 63.

[103] Sne, N.; Ondiveeran, H.K.; Fox-Robichaud, A. IDrugs., 2002, 5, 91.

[104] Weitz, J.I.; Hirsh, J.; Samama, M.M. Chest, 2004, 126, 265S.

[105] Dennis, M.S.; Eigenbrot, C.; Skelton, N.J.; Ultsch, M.H.; Santell, L.; Dwyer, M.A.; O'Connell, M.P.; Lazarus, R.A. Nature, 2000, 404, 465.

[106] Dennis, M.S.; Roberge, M.; Quan, C.; Lazarus, R.A. Biochemistry, 2001, 40, 9513.

[107] Roberge, M.; Santell, L.; Dennis, M.S.; Eigenbrot, C.; Dwyer, M.A.; Lazarus, R.A. Biochemistry, 2001, 40, 9522 .

[108] Stassens, P.; Bergum, P.W.; Gansemans, Y.; Jespers, L.; Laroche, Y.; Huang, S.; Maki, S.; Messens, J.; Lauwereys, M.; Cappello, M.; Hotez, P.J.; Lasters, I.; Vlasuk, G.P. Proc. Natl. Acad. Sci. USA, 1996, 93, 2149.

[109] Bergum, P.W.; Cruikshank, A.; Maki, S.L.; Kelly, C.R.; Ruf, W.; Vlasuk, G.P. J. Biol. Chem., 2001, 276, 10063.

[110] Buddai, S.K.; Toulokhonova, L.; Bergum, P.W.; Vlasuk, G.P.; Krishnaswamy, S. J. Biol. Chem., 2002, 277, 26689.

[111] Lee, A.Y.Y.; Vlasuk, G.P. J. Int. Med., 2003, 254, 313.

[112] Murakami, M.T.; Rios-Steiner, J.; Weaver, S.E.; Tulinsky, A.; Geiger, J.H.; Arni, R.K. J. Mol. Biol. 2007, 366, 602.

[113] Giugliano, R.P.; Wiviott, S.D.; Stone, P.H.; Simon, D.I.; Schweiger, M.J Bouchard, A.; Leesar, M.A.; Goulder, M.A.; Deitcher, S.R.; McCabe, C.H.; Braunwald, E. J. Am. Coll. Cardiol., 2007, 49, 2398

[114] Moons, A.H.; Peters, R.J.; Bijsterveld, N.R.; Piek, J.J.; Prins, M.H.; Vlasuk, G.P.; Rote, W.E.; Büller, H.R. J. Am. Coll. Cardiol., 2003, 41, 2147.

[115] Jakobsen, P.; Pedersena, B.R.; Persson, E. Bioorg. Med. Chem., 2000, 8, 2095 .

[116] Jakobsen, P.; Horneman, A.M.; Persson, E. Bioorg. Med. Chem., 2000, 8, 2803 . 
[117] Kohrt, J.T.; Filipski, K.J.; Cody, W.L.; Cai, C.; Dudley, D.A.; Van Huis, C.A.; Willardsen, J.A.; Narasimhan, L.S.; Zhang, E.; Rapundalo, S.T.; SaiyaCork, K.; Leadley, R.J.; Edmunds, J.J. Bioorg. Med. Chem. Lett., 2006, 16, 1060 .

[118] Kohrt, J.T.; Filipski, K.J.; Cody, W.L.; Cai, C.; Dudley, D.A.; Van Huis, C.A.; Willardsen, J.A.; Rapundalo, S.T.; Saiya-Cork, K.; Leadley, R.J.; Narasimhan, L.; Zhang, E.; Whitlow, M.; Adler, M.; McLean, K.; Chou, Y.L.; McKnight, C.; Arnaiz, D.O.; Shaw, K.J.; Light, D.R.; Edmunds, J.J. Bioorg. Med. Chem. Lett., 2005, 15, 4752.

[119] Zbinden, G.K.; Banner, D.W.; Hilpert, K.; Himber, J.; Lavé, T.; Riederer, M.A.; Stahl, M.; Tschopp, T.B.; Obst-Sander, U. Bioorg. Med. Chem., 2006, $14,5357$.

[120] Zbinden, K.G.; Obst-Sander, U.; Hilpert, K.; Kühne, H.; Banner, D.W.; Böhm, H.J.; Stahl, M.; Ackermann, J.; Alig, L.; Weber, L.; Wessel, H.P.; Riederer, M.A.; Tschopp, T.B.; Lavé, T. Bioorg. Med. Chem. Lett., 2005, 15, 5344 .

[121] Parlow, J.J.; Dice, T.A.; Lachance, R.M.; Girard, T.J.; Stevens, A.M.; Stegeman, R.A.; Stallings, W.C.; Kurumbail, R.G.; South, M.S. J. Med. Chem., 2003, 46, 4043 .

[122] South, M.S.; Case, B.L.; Wood, R.S.; Jones, D.E.; Hayes, M.J.; Girard, T.J.; Lachance, R.M.; Nicholson, N.S.; Clare, M.; Stevens, A.M.; Stegeman, R.A.; Stallings, W.C.; Kurumbail, R.G.; Parlow, J.J. Bioorg. Med. Chem. Lett., 2003, 13, 2319.

[123] Parlow, J.J.; Case, B.L.; Dice, T.A.; Fenton, R.L.; Hayes, M.J.; Jones, D.E.; Neumann, W.L.; Wood, R.S.; Lachance, R.M.; Girard, T.J.; Nicholson, N.S.; Clare, M.; Stegeman, R.A.; Stevens, A.M.; Stallings, W.C.; Kurumbail, R.G.; South, M.S. J. Med. Chem., 2003, 46, 4050.

[124] Young W.B.; Kolesnikov, A.; Rai, R.; Sprengeler, P.A.; Leahy, E.M.; Shrader, W.D.; Sangalang, J.; Burgess-Henry, J.; Spencer, J.; Elrod, K.; Cregar, L. Bioorg. Med. Chem. Lett., 2001, 11, 2253.

[125] South, M.S.; Dice, T.A.; Girard, T.J.; Lachance, R.M.; Stevens, A.M.; Stegeman, R.A.; Stallings, W.C.; Kurumbail, R.G.; Parlow, J.J. Bioorg. Med. Chem. Lett., 2003, 13, 2363.

[126] South, M.S.; Case, B.L.; Wood, R.S.; Jones, D.E.; Hayes, M.J.; Girard, T.J.; Lachance, R.M.; Nicholson, N.S.; Clare, M.; Stevens, A.M.; Stegeman, R.A.; Stallings, W.C.; Kurumbail, R.G.; Parlow, J.J. Bioorg. Med. Chem. Lett., 2003, 13, 2319 .

[127] Suleymanov, O.D.; Szalony, J.A.; Salyers, A.K.; LaChance, R.M.; Parlow, J.J.; South, M.S.; Wood, R.S.; Nicholson, N.S. J. Pharmacol. Exp. Ther., 2003, 306, 1115 .

[128] Schweitzer, B.A.; Neumann, W.L.; Rahman, H.K.; Kusturin, C.L.; Sample, K.R.; Poda, G.I.; Kurumbail, R.G.; Stevens, A.M.; Stegeman, R.A.; Stallings, W.C.; South, M.S. Bioorg. Med. Chem. Lett., 2005, 15, 3006.

[129] Parlow, J.J.; Stevens, A.M.; Stegeman, R.A.; Stallings, W.C.; Kurumbail, R.G.; South, M.S. J. Med. Chem., 2003, 46, 4297.

[130] Parlow, J.J.; Kurumbail, R.G.; Stegeman, R.A.; Stevens, A.M.; Stallings, W.C.; South, M.S. J., Med. Chem., 2003, 46, 4696.

[131] Parlow, J.J.; Kurumbail, R.G.; Stegeman, R.A.; Stevens, A.M.; Stallings, W.C.; South, M.S. Bioorg. Med. Chem. Lett., 2003, 13, 3721

[132] Shrader, W.D.; Kolesnikov, A.; Burgess-Henry, J.; Rai, R.; Hendrix, J.; Hu, H.; Torkelson, S.; Ton, T.; Young, W.B.; Katz, B.A.; Yu, C.; Tang, J.; Cabuslay, R.; Sanford, E.; Janc, J.W.; Sprengeler, P.A. Bioorg. Med. Chem. Lett., 2006, 16, 1596.
[133] Buckman, B.O.; Chou, Y.L.; McCarrick, M.; Liang, A.; Lentz, D.; Mohan, R.; Morrissey, M.M.; Shaw, K.J.; Trinh, L.; Light, D.R. Bioorg. Med. Chem. Lett., 2005, 15, 2249.

[134] Sagi, K.; Fujita, K.; Sugiki, M.; Takahashi, M.; Takehana, S.; Tashiro, K.; Kayahara, T.; Yamanashi, M.; Fukuda, Y.; Oono, S.; Okajima, A.; Iwata, S.; Shoji, M.; Sakurai, K. Bioorg. Med. Chem., 2005, 13, 1487.

[135] Kadono, S.; Sakamoto, A.; Kikuchi, Y; Oh-Eda, M.; Yabuta, N.; Yoshihashi, K.; Kitazawa, T.; Suzuki, T.; Koga, T.; Hattori, K.; Shiraishi, T.; Haramura, M.; Kodama, H.; Ono, Y.; Esaki, T.; Sato, H.; Watanabe, Y.; Itoh, S.; Ohta, M.; Kozono, T. Biochem. Biophys. Res. Commun., 2005, 326, 859.

[136] Kadono, S.; Sakamoto, A.; Kikuchi, Y.; Oh-eda, M.; Yabuta, N.; Koga, T. Hattori, K.; Shiraishi, T.; Haramura, M.; Kodama, H.; Esaki, T.; Sato, H.; Watanabe, Y.; Itoh, S.; Ohta, M.; Kozono, T. Biochem. Biophys. Res. Commun., 2004, 324, 1227.

[137] Kadono, S.; Sakamoto, A.; Kikuchi, Y.; Oh-eda, M.; Yabuta, N.; Yoshihashi, K.; Kitazawa, T.; Suzuki, T.; Koga, T.; Hattori, K.; Shiraishi, T.; Haramura, M.; Kodama, H.; Ono, Y.; Esaki, T.; Sato, H.; Watanabe, Y.; Itoh, S.; Ohta, M.; Kozono, T. Biochem. Biophys. Res. Commun., 2005, 327, 589.

[138] Klingler, O.; Matter, H.; Schudok, M.; Donghi, M.; Czech, J.; Lorenz, M.; Nestler, H.P.; Szillat, H.; Schreuder, H. Bioorg. Med. Chem. Lett., 2004, 14, 3715 .

[139] Klingler, O.; Matter, H.; Schudok, M.; Bajaj, S.P.; Czech, J.; Lorenz, M.; Nestler, H.P.; Schreuder, H.; Wildgoose, P. Bioorg. Med. Chem. Lett., 2003, 13, 1463.

[140] Miura, M.; Seki, N.; Koike, T.; Ishihara, T.; Niimi, T.; Hirayama, F.; Shigenaga, T.; Sakai-Moritani, Y.; Kawasaki, T.; Sakamoto, S.; Okada, M.; Ohta, M.; Tsukamoto, S. Bioorg. Med. Chem., 2006, 14, 7688.

[141] Miura, M.; Seki, N.; Koike, T.; Ishihara, T.; Niimi, T.; Hirayama, F.; Shigenaga, T.; Sakai-Moritani, Y.; Tagawa, A.; Kawasaki, T.; Sakamoto, S.; Okada, M.; Ohta, M.; Tsukamoto, S. Bioorg. Med. Chem., 2007, 15, 160.

[142] Riggs, J.R.; Hu, H.; Kolesnikov, A.; Leahy, E.M.; Wesson, KE.; Shrader, W.D.; Vijaykumar, D.; Wahl, T.A.; Tong, Z.; Sprengeler, P.A.; Green, M.J.; Yu, C.; Katz, B.A.; Sanford, E.; Nguyen, M.; Cabuslay, R.; Young, W.B. Bioorg. Med. Chem. Lett., 2006, 16, 3197.

[143] Rai, R.; Kolesnikov, A.; Sprengeler, P.A.; Torkelson, S.; Ton, T.; Katz, B.A.; Yu, C.; Hendrix, J.; Shrader, W.D.; Stephens, R.; Cabuslay, R.; Sanford, E.; Young, W.B. Bioorg. Med. Chem. Lett., 2006, 16, 2270.

[144] Vijaykumar, D.; Rai, R.; Shaghafi, M.; Ton, T.; Torkelson, S.; Leahy, E.M.; Riggs, J.R.; Hu, H.; Sprengeler, P.A.; Shrader, W.D.; O'Bryan, C.; Cabuslay, R.; Sanford, E.; Gjerstadt, E.; Liu, L.; Sukbuntherng, J.; Young, W.B. Bioorg. Med. Chem. Lett., 2006, 16, 3829.

[145] Young, W.B.; Mordenti, J.; Torkelson, S.; Shrader, W.D.; Kolesnikov, A.; Rai, R.; Liu, L.; Hu, H.; Leahy, E.M.; Green, M.J.; Sprengeler, P.A.; Katz, B.; Janc, J.W.; Marzec, U.M.; Hanson, S.R. Bioorg. Med. Chem. Lett., 2006, 16, 2037.

[146] Hu, H; Kolesnikov, A; Riggs, J.R; Wesson, K.E.; Stephens, R.; Leahy, E.M.; Shrader, W.D.; Sprengeler, P.A.; Green, M.J.; Sanford, E.; Nguyen, M.; Gjerstad, E.; Cabuslay, R.; Young, W.B. Bioorg., Med. Chem. Lett., 2006, 16, 4567.

[147] Carroll, A.R.; Pierens, G.K.; Fechner, G.; De Almeida Leone, P.; Ngo, A.; Simpson, M.; Hyde, E.; Hooper, J.N.; Boström, S.L.; Musil, D.; Quinn, R.J. J. Am. Chem. Soc., 2002, 124, 13340.

[148] Hanessian S.; Margarita, R.; Hall, A.; Johnstone, S.; Tremblay, M.; Parlanti, L. J. Am. Chem. Soc., 2002, 124, 13342.

[149] Carroll, A.R.; Buchanan, M.S.; Edser, A.; Hyde, E.; Simpson, M.; Quinn, R.J. J. Nat. Prod., 2004, 67, 1291. 